\title{
Numerical Simulations of Thermoplastic Burning Rate: Effect of Property Variations and the Inferred Effective Heat of Gasification
}

\author{
Gregory Linteris
}

This publication is available free of charge from:

http://dx.doi.org/10.6028/NIST.TN.1929 
NIST Technical Note 1929

\section{Numerical Simulations of Thermoplastic Burning Rate: Effect of Property Variations and the Inferred Effective Heat of Gasification}

Gregory Linteris

Energy and Environment Division

Engineering Laboratory

This publication is available free of charge from:

http://dx.doi.org/10.6028/NIST.TN.1929

September 2016

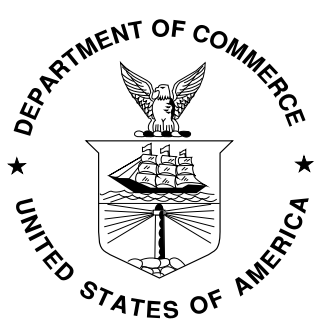

U.S. Department of Commerce

Penny Pritzker, Secretary

National Institute of Standards and Technology Willie May, Under Secretary of Commerce for Standards and Technology and Director 
Certain commercial entities, equipment, or materials may be identified in this document in order to describe an experimental procedure or concept adequately. Such identification is not intended to imply recommendation or endorsement by the National Institute of Standards and Technology, nor is it intended to imply that the entities, materials, or equipment are necessarily the best available for the purpose.

National Institute of Standards and Technology Technical Note 1929 Natl. Inst. Stand. Technol. Tech. Note 1929, 41 pages (September 2016) CODEN: NTNOEF

This publication is available free of charge from: http://dx.doi.org/10.6028/NIST.TN.1929 


\title{
NUMERICAL SIMULATIONS OF POLYMER BURNING RATE: EFFECT OF PROPERTY VARIATIONS AND THE INFERRED EFFECTIVE HEAT OF GASIFICATION*
}

\author{
Gregory Linteris \\ Energy and Environment Division \\ National Institute of Standards and Technology \\ 100 Bureau Dr. Stop 8631 \\ Gaithersburg, MD 20899-8631
}

\begin{abstract}
The mass loss rate of Poly(methyl methacrylate) exposed to known radiant fluxes is simulated with two recently-developed numerical codes, the NIST Fire Dynamics Simulator (FDS) and the FAA ThermaKin. The influence of various material properties (thickness, thermal conductivity, specific heat, absorption of infrared radiation, heat of reaction) on mass loss history is assessed, via their effect on the ignition time, average mass loss rate, peak mass loss rate, and time to peak. The two codes predict the influence of material parameters on the MLR in the order of decreasing importance: heat of reaction, thickness, specific heat, absorption coefficient, thermal conductivity, and activation energy of the polymer decomposition. Changes in the material properties also influence the MLR curves by switching the sample from thermally thick to thermally thin. The two numerical codes are generally in very good agreement for their predictions of the MLR versus time curves, except when in-depth absorption of radiation was important. The influence of two of these parameters on the effective heat of gasification (extracted from the mass loss rate at differing external heat fluxes) is also assessed by comparing the effective heat of gasification to the heat of gasification input into the calculations; the ratio of these is highest for calculations in which the radiant energy is absorbed on the surface and the material decomposition has a low activation energy, for which it reaches 1.3, but is lower for other cases. Modifying the method used to obtain the effective heat of gasification by basing it on the net energy delivered to the polymer brings it much closer to the values input into the calculation.
\end{abstract}

\section{KEYWORDS:}

Material flammability, heat release rate, heat of gasification, polymer burning rate

\footnotetext{
${ }^{*}$ Official contribution of NIST, not subject to copyright in the United States.
} 


\section{NOMENCLATURE}

$\Delta \mathrm{H}_{\mathrm{g}}$ - heat of gasification, $\mathrm{kJ} \mathrm{kg}^{-1}$

$\Delta \mathrm{H}_{\text {reac }}$ - heat of reaction, $\mathrm{kJ} \mathrm{kg}^{-1}$

$\Delta \mathrm{H}_{\mathrm{v}}$ - heat of vaporization, $\mathrm{kJ} \mathrm{kg}^{-1}$

$\mathrm{T}$ - temperature, $\mathrm{K}$

$\dot{m}^{\prime \prime}$ - mass loss rate, $\mathrm{g} \mathrm{m}^{-2} \mathrm{~s}^{-1}$

$\dot{q}_{\text {net }}^{\prime \prime}$ - net heat flux, $\mathrm{kW} \mathrm{m} \mathrm{m}^{-2} \mathrm{~s}^{-1}$

$\dot{q}_{f t}^{\prime \prime}$ - heat flux from flame to surface, $\mathrm{kW} \mathrm{m}^{-2} \mathrm{~s}^{-1}$

$\dot{q}_{\text {loss }}^{\prime \prime}$-heat flux from surface to ambient, $\mathrm{kW} \mathrm{m}^{-2} \mathrm{~s}^{-1}$

$\dot{q}_{\text {ext }}^{\prime \prime}$ - externally applied heat flux, $\mathrm{kW} \mathrm{m}^{-2} \mathrm{~s}^{-1}$

$k$ - thermal conductivity, $\mathrm{W} \mathrm{m} \mathrm{s}^{-1}$

$c$ - specific heat, $\mathrm{kJ} \mathrm{kg}^{-1} \mathrm{~K}^{-1}$

$E_{a}-$ Arrhenius activation energy of one-step material decomposition

A - Arrhenius pre-exponential term for one-step material decomposition

$\mathrm{R}$ - Universal gas constant, $\mathrm{kJ} \mathrm{mol}^{-1} \mathrm{~K}^{-1}$

$\mathrm{S}$ - sample thickness, $\mathrm{m}$

Greek Symbols

$\alpha$ - absorption coefficient, $\mathrm{m}^{-1}$

$\delta$ - thermal thickness (with respect to mass loss), m

$\delta_{\mathrm{t}}$-thermal conduction length, $\mathrm{m}$

$\tau_{\text {ign }}-$ ignition time, $\mathrm{s}$

\section{Abbreviations}

MLR - mass loss rate

$\mathrm{MLR}_{\mathrm{av}}$ - average mass loss rate

EHF - external heat flux

\section{INTRODUCTION}

The prediction of fuel generation rates from burning solid materials is an important component of models for fire growth in buildings. Validation of these sub-grid models is often done via predictions of the mass loss rate for small samples subjected to a known radiant heat flux, in standard devices such as the cone calorimeter [1], the FM Global Fire Propagation Apparatus (FPA)[2], and other devices [3]. The mass loss rate of thermoplastics in these devices has been predicted analytically and numerically by various groups $[4,5,6,7,8,9,10,11,12]$.

Accurate prediction of the mass loss rate (MLR) requires the input data for the physical parameters of the polymer used in the model. In general, two approaches are being taken to supply these parameters:

estimating them from the mass loss rate (or temperature) data obtained in the experiments to be modeled 
themselves [4,7,8] (sometimes with parameter optimization algorithms [13]), or measuring the individual parameters with separate experimental devices [5,9,12]. In either case, it is of value to understand the sensitivity of the mass loss rate to the individual parameters in the model. In the former case, such knowledge can allow one to design specific experimental runs for the most accurate extraction of certain parameters. In the latter case, knowing the sensitivity to each of the parameters can allow one to spend the limited resources on measuring the most relevant parameters, and to use simpler methods or estimations for parameters less important. Finally, mass loss rate curves and ignition times provided here can be used as an aid in interpreting cone calorimeter data. The present results are in the spirit of previous work in which the variation of mass loss rate with thickness [14], and with heat flux [15] have been illustrated, and extend the phenomenological illustration to additional parameters as suggested by Schartel $[16,17]$.

Recently, Stoliarov et al. [18] have performed sensitivity calculations and reported the results of input parameter variation in terms of their effects on global parameters (such as the peak heat release, average heat release, etc.). The present investigation seeks to provide additional information beyond that in ref. [18], by presenting the data as the time-dependent mass loss rate. The collection of simulated mass loss curves can serve as a database illustrating the effects of changes in the parameters on the burning behavior, providing physical insight to developers of less flammable materials. Such calculations are easier and faster than the comparable experiments would be, and can be performed with individual parameters changed in isolation (in ways not always possible in experiments). In the second part of the paper, the simulation techniques are employed to examine the accuracy of one method of extracting the effective heat of gasification from experiments done in a radiant heating device.

While much of the mass loss and ignition behavior of PMMA under constant heat flux is already known, often, not all of the physical effects are included in the analysis, and when many are, it is usually not possible to obtain closed-form solutions to the equations. Hence, it seemed of value to provide a compendium of the effects of multiple parameters on the thermal decomposition of PMMA. In the discussion, emphasis is placed on those conditions for which the behavior deviates from that expected based on simple models.

\section{APPROACH}

The time-dependent mass loss rate of a thermoplastic material subjected to a known radiant flux has been simulated. Two numerical simulation codes describing the solid phase have been used: the NIST Fire Dynamics Simulator (FDS 5.3.0. SVN 3193) [19] and the FAA Thermo-kinetic Model of Burning (ThermaKin) [20,21]. Poly(methyl methacrylate) (PMMA) was selected as the base polymer for simulation, since it is a typical thermoplastic, is nearly a standard material in flammability studies, and its properties are relatively well studied. The simulations of the MLR were used in the present work to examine how variations in the input parameters affect: 1.) the time-dependent MLR and the ignition time (Part I); and 2.) the value of the effective heat of gasification extracted from the mass loss data using the method of Tewarson and Pion[4].

The input parameters in the models are shown in Table 1. Part I of the present study (parametric analysis) uses the nominal parameter values of Rhodes and Quintiere [8] as a base-case (column three), and these parameters are varied over the range of values as indicated in the column four. Part II of the present study uses the parameter values of Staggs [22] (to allow more direct comparisons with the calculations of Staggs) and they are listed in the column five; some were varied over the range indicated in column six. The major differences between the two nominal sets are the $36 \%$ lower $c$ and the $58 \%$ lower $\Delta \mathrm{H}_{\mathrm{g}}$ in Staggs analysis. 
Typically, the parameters in Table 1 are varied over a factor of five, about a factor of 2 to 2.5 above and below the nominal value. This is a somewhat larger range than experienced by typical polymers [18] and was selected to provide guidance in the event that new, composite polymers are produced with a wider range of properties than in the pure polymers.

The calculated curves of MLR versus time are characterized by the ignition time, average MLR, peak MLR, and time to peak MLR. In the present analyses, the ignition time $\tau_{\text {ign }}$ is defined as the time at which the mass loss rate has first achieved a value of $3 \mathrm{~g} \mathrm{~s}^{-1} \mathrm{~m}^{-2}$, as suggested in ref. [23]. The average mass loss rate $\left(M L R_{a v}\right)$ is defined as the integral of the MLR versus time curve, between the time at which the flux is applied, and the time at which the MLR has decreased back to the mass loss at ignition ( $3 \mathrm{~g} \mathrm{~s}^{-}$ $\left.{ }^{1} \mathrm{~m}^{-2}\right)$. The parameters varied are the material properties: thermal conductivity $(\mathrm{k})$, specific heat $(c)$, extinction coefficient $(\alpha)$, heat of reaction $\left(\Delta \mathrm{H}_{\text {reac }}\right)$, and the Arrhenius pre-exponential term $(\mathrm{A})$ and activation energy $\left(E_{a}\right)$ for the one-step material decomposition reaction. The experimental parameters varied are the external heat flux (EHF) and material thickness (S).

The most important material property affecting the burning rate of a polymer is its heat of gasification $\Delta \mathrm{H}_{\mathrm{g}}$ [24]. For a simple vaporizing material the heat of gasification can be described by $\Delta H_{g}=\int_{T_{a}}^{T_{v}} c(T) d T+\Delta H_{v}$ in which the first part is the sensible heat in raising the material from the ambient temperature $T_{a}$ up to the temperature at which it vaporizes $T_{v}$, and the second part is the heat of vaporization $\Delta \mathrm{H}_{\mathrm{v}}$. This simple model is often used to describe more complicated solid materials which undergo endothermic pyrolysis reactions to form gas-phase products, by substituting a pyrolysis temperature $\mathrm{T}_{\mathrm{p}}$, and a heat of reaction $\Delta \mathrm{H}_{\text {reac }}$ (i.e., a heat of decomposition in going from the solid directly to the gas-phase species).

$$
\Delta H_{g}=\int_{T_{a}}^{T_{p}} c(T) d T+\Delta H_{\text {reac }}
$$

Eq. 1

The assumption is often made that the material undergoes one-step decomposition to gaseous products, with either an infinite rate or a finite rate given by an Arrhenius rate expression. Methods have been developed to estimate the heat of gasification, either from measurements of the steady burning rate of the polymer exposed to different external fluxes (and called the "effective" heat of gasification, $\Delta \mathrm{H}_{\mathrm{g}}{ }^{\text {(eff) }}$ [4]), or by differential scanning calorimetry [25,26].

The use of cone calorimeter (or FPA) data to estimate the effective heat of gasification has great utility and is widely used [27]; the method is straightforward, and can easily be part of other flammability tests for the sample. In the method of Tewarson and Pion [4], the steady mass loss rate is plotted against EHF, and the inverse of the slope is taken as $\Delta \mathrm{H}_{\mathrm{g}}{ }^{\text {(eff) }}$. Nonetheless, the method is based on some simplifications in the polymer's behavior, and it is useful to understand the effects of other parameters on the accuracy of the technique. In particular, the method assumes that at the different levels of the external heat flux, both the heat feedback from the flame to the polymer and the surface heat losses from the polymer are constant (i.e., constant surface temperature). Also, any radiation blocking by gasification products is assumed constant.

Using an analytical solution for the steady mass loss rate, Staggs generated synthetic mass loss data, and examined the accuracy for the method of Tewarson and Pion for the case of PMMA and polyethylene (PE). He found that $\Delta \mathrm{H}_{\mathrm{g}}{ }^{\text {(eff) }}$ was $20 \%$ to $40 \%$ higher than the values of $\Delta \mathrm{H}_{\mathrm{g}}$ input into the model. Since $\Delta H_{g}$ is the most important parameter affecting the mass loss variation with time, and since it is commonly found using the method of Tewarson and Pion , it is of interest to examine the influence of other parameters (besides the few cases examined by Staggs) on the accuracy of the technique. 
In the approach taken in Part II, the mass loss rates vs. time are generated numerically for a range of EHF, using known input values for $c, \Delta \mathrm{H}_{\text {reac }}$, and hence $\Delta \mathrm{H}_{\mathrm{g}}$. Then, using these synthetic MLR curves, the effective heat of gasification, $\Delta \mathrm{H}_{\mathrm{g}}{ }^{\text {(eff) }}$, is extracted from these curves, and compared to the values of $\Delta \mathrm{H}_{\mathrm{g}}$ which were input. By repeating the calculations with different values of the material properties, the accuracy of the extracted value of $\Delta \mathrm{H}_{\mathrm{g}}{ }^{\text {(eff) }}$ is assessed, along with its variation with material properties. Since there is no flame in the simulations (only radiant heat), the inaccuracies in the method of Tewarson and Pion, with respect to variations in the flame heat feedback and radiation blocking, can be avoided. Also, influences on the mass loss rate due to charring, bubble formation, and other effects, are avoided, since they are neglected in the calculation.

\section{NUMERICAL CALCULATIONS}

In the calculations with FDS or ThermaKin, the time-dependent 1-D heat transfer equation is solved for the solid phase, subject to mass (and energy) changes from reaction at any depth. There was only one solid-phase component, corresponding to PMMA, with thermal conductivity and specific heat either given by a linear correlation [12], or by the average value between the initial temperature and the pyrolysis temperature. Thermal decomposition was via a one-step Arrenhius-type reaction (rate = $A \exp \left(-E_{a} / R T\right)$ ) to a single gas-phase component, and there was no resistance to transport of the reacted polymer to the surface. Surface reflection and re-radiation are included. The initial temperature of the polymer was set to $293 \mathrm{~K}$, the surface emissivity was set to 0.95 (1 in Part II), and the sample backside was insulated (adiabatic) with a reflectivity of 1 (i.e., a foil-wrapped sample). The convective heat transfer coefficient of the heated face was set to zero for the parametric analysis in Part I (to allow easy comparison of the FDS and ThermaKin results), and to $10 \mathrm{~W} \mathrm{~m}^{-1} \mathrm{~K}^{-1}$ for the analysis in Part II (to facilitate comparisons with the analysis of Staggs).

In the ThermaKin calculations, the calculation was 1 -D, the finite element objects were $5 \times 10^{-5} \mathrm{~m}$ thick, and the time step was $0.025 \mathrm{~s}$. Reducing these by a factor of four had no significant effect on the MLR, and only about a $3 \%$ effect on the ignition time (which was more sensitive). In-depth absorption of radiation was treated using a random-sampling technique in which the energy is deposited at random locations in the 1-D sample, following a Beer's law attenuation, with energy emission then following from the same location. Because of the discrete (and random) treatment of radiation, the calculated mass loss (sampled every 2 seconds) had fluctuations, so the data were smoothed (running average) for $8 \mathrm{~s}$.

In the FDS calculations, all gas-phase reaction was turned off by setting the mass fraction of $\mathrm{O}_{2}$ in the air to 0.01 and a minimum gas-phase mesh was used. The time step was set to $0.1 \mathrm{~s}$, except for ignition time calculations, for which it was set to 0.005 ; this value yielded ignition times within $1 \%$ of those with a time step of $0.01 \mathrm{~s}$. The parameters used for the solid-phase calculation (which has adaptive gridding) are: STRETCH_FACTOR $=2.0$, CELL_SIZE_FACTOR $=0.06$, and REGRID_FACTOR $=1.0$, which provide the most grid cells, of the most non-uniform size, and which are re-grided the most often. The initial gridding gave a smallest grid size of $1.67 \times 10^{-5} \mathrm{~m}$ to $3.33 \times 10^{-5} \mathrm{~m}$ (depending upon the case).

The performance of ThermaKin has recently been validated in predictions of the gasification rate of poly(methylmethacrylate), high-impact polystyrene (HIPS), and high density polyethylene (HDPE) [12], and it is used predominantly in the present work. Calculations with FDS are provided for comparison purposes. 


\section{RESULTS}

\subsection{PART 1: Parametric Analyses}

\subsubsection{Mass Loss Rate vs. Time}

\section{External Heat Flux (EHF)}

The external heat flux is not a material property, but it is worthwhile to first illustrate the effect of this parameter on the mass loss rate. Figure 1 shows mass loss rate for PMMA with the nominal properties of Table 1 exposed to an EHF of $(21,50,100,150$, or 200$) \mathrm{kW} / \mathrm{m}^{2}$. Simple analytical models of the thermoplastic burning rate [4] show that the steady mass loss rate $\dot{m} "$ is given by

$$
M L R=\frac{d m^{\prime \prime}}{d t}=\dot{m}^{\prime \prime}=\frac{\dot{q}_{n e t} "}{\Delta H_{g}}
$$

where $\dot{q}_{\text {net }}^{\prime \prime}$ is the net external heat flux, and $\dot{q}_{\text {net }}^{\prime \prime}=\dot{q}_{f l}^{\prime \prime}+\dot{q}_{\text {ext }}^{\prime \prime}-\dot{q}_{\text {loss }}^{\prime \prime}$, in which $\dot{q}_{f l}^{\prime \prime}$ is the heat feedback from the flame to the surface, $\dot{q}_{\text {ext }}^{\prime \prime}$ is the external heat flux, and $\dot{q}_{\text {loss }}$ is the heat lost from the surface by convection and radiation. The burning time $t_{\text {burn }}$ is given by $\rho S \Delta H_{g} / \dot{q}_{\text {net }}$, where $\rho$ and $S$ are the density and thickness of the1-D sample. Since the heat losses and flame heat feedback are relatively constant as compared to the changes in the external flux $\dot{q}_{e x t}^{\prime \prime}$, the mass loss rate is approximately proportional to both the net and incident heat flux (as indicated in Figure 1), and the burning time is inversely proportional to $\dot{q}_{e x t}^{\prime \prime}$.

The thermal thickness $(\delta)$ of a material under steady surface regression can be given [28] by

$$
\delta=\frac{2 k \Delta H_{g}}{C_{p} \dot{q}_{n e t}^{\prime \prime}} .
$$

A sample is thermally thin if $S / \delta \leq 1$ and thermally thick if $S / \delta>1$. For the nominal PMMA properties, the thermal penetration depth is about $(45,13.7,6.3,4.1$, and 3.0) $\mathrm{mm}$ for incident fluxes of $(21,50,100$, 150 , and 200$) \mathrm{kW} / \mathrm{m}^{2}$ (assuming a surface temperature $\left(\mathrm{T}_{\mathrm{s}}\right)$ of $352^{\circ} \mathrm{C}$ and no convective losses). Including the surface convective heat losses, about $3 \mathrm{~kW} / \mathrm{m}^{2}$ for PMMA, would increase the thermal penetration depth by about $\left(35,9,4,2\right.$, and 2) \% for these incident fluxes. The low flux case $\left(21 \mathrm{~kW} / \mathrm{m}^{2}\right)$ in Figure 1 is thermally thin, while the others are thermally thick. Another way to show the thin vs. thick behavior is to normalized the MLR curves by the steady-burning value (Eq. 2) for the mass loss rate ( $\dot{q}_{n e t}^{\prime \prime} / \Delta H_{g}$ ), and for the burning time $\rho S \Delta H_{g} / \dot{q}_{\text {net }}^{\prime \prime}$. This is shown in the inset of Figure 1; the curves are reasonably coincident for the thermally thick cases, but deviate for the thinner cases.

These results illustrate that for $25.4 \mathrm{~mm}$ thick PMMA, the sample response for fluxes in the EHF range of $21 \mathrm{~kW} / \mathrm{m}^{2}$ to $75 \mathrm{~kW} / \mathrm{m}^{2}$ will readily shift from thermally thick to thermally thin as the various parameters are changed. This will become apparent as the mass loss rate curves are discussed below. (Note that the absorption coefficient would enter in the denominator of Eq. 3 above, since a low value of $\alpha$ acts like high thermal conductivity, sending heat more readily in-depth in the sample.) For all values of the flux, 
the peak MLR is $38 \%$ to $45 \%$ higher than the average MLR, and the time to peak MLR scales with the burning time.

\section{Sample Thickness}

Sample thickness is also not a material property, but is useful to examine. Figure 2 shows the mass loss rate of nominal PMMA at EHF values of $21 \mathrm{~kW} / \mathrm{m}^{2}$ (left frame) and $100 \mathrm{~kW} / \mathrm{m}^{2}$ (right frame) for sample thickness of $(2,4,8,15$, and 32) $\mathrm{mm}$. At the low flux, the sample is always thermally thin; at the higher flux, the behavior becomes thermally thin as the sample thickness decreases to about $8 \mathrm{~mm}$, which is consistent with the numbers given above. Both the average and peak MLR are nearly unchanged as S decreases, except for the thinnest samples for which both the peak and the average MLR drop off, the average somewhat faster, about $(30,40,48$, and 56$) \%$ lower at $(21,50,100$, and 200$) \mathrm{kW} / \mathrm{m}^{2}$, for the $2 \mathrm{~mm}$ sample as compared to the $32 \mathrm{~mm}$ sample. This is due to insufficient thickness for complete absorption of the thermal radiation. For example, the dotted lines in Figure 2 illustrate the results for $S=$ $2 \mathrm{~mm}$ and $\alpha=50000 \mathrm{~m}^{-1}$ (surface absorption), for which the peak and average MLR are restored closer to the values at larger $S$, only $(-5,2,7$, and 16$) \%$ lower for the $2 \mathrm{~mm}$ sample as compared to the $32 \mathrm{~mm}$ sample at $(21,50,100$, and 200$) \mathrm{kW} / \mathrm{m}^{2}$, respectively.

\section{Heat of Reaction, $\Delta \mathrm{H}_{\text {reac }}$}

The heat of reaction has the largest effect on the mass loss rate of any material property. Figure 3 shows the mass loss rate as a function of time for PMMA with an EHF of a.) $21 \mathrm{~kW} / \mathrm{m}^{2}$ and b.) $100 \mathrm{~kW} / \mathrm{m}^{2}$. The different curves in the figures show the results for $\Delta H_{\text {reac }}=(1000,2000,3000,4000$, and 5000$) \mathrm{kJ} \mathrm{kg}^{-1}$. For higher flux, the behavior is always thermally thick, while for low flux, the behavior is thermally thin for all values of $\Delta H_{\text {reac }}$ except $1000 \mathrm{~kJ} \mathrm{~kg}^{-1}$, for which it's almost thermally thick. At either $21 \mathrm{~kW} / \mathrm{m}^{2}$ or $100 \mathrm{~kW} / \mathrm{m}^{2}$, and the lowest value of $\Delta H_{\text {reac }}$, (upper most curves), the peak heat release is much higher than the average heat release as compared to the other cases of $\Delta H_{\text {reac }}$. This is because for low $\Delta H_{\text {reac }}$, the sensible part becomes a larger fraction of $\Delta \mathrm{H}_{\mathrm{g}}$, and the transient effect from the pre-heating of the indepth layers of the polymer due to thermal diffusion becomes larger relative to the enthalpy change due to decomposition. For the nominal polymer properties, the algebraic relationship in Eq. 2 shows MLR $\sim \Delta \mathrm{H}_{\mathrm{g}}{ }^{\mathrm{n}}$, where $\mathrm{n}=0.72$, which is close to the behavior shown in Figure 3, where the value of $\mathrm{n}$ ranges from 0.64 to 0.80 , depending upon EHF.

\section{Activation Energy, Ea}

Variations in the activation energy of the PMMA decomposition reaction can increase or decrease the MLR, with both the magnitude and direction depending upon the value of the external heat flux. (All of the above results are for $E_{a}=209 \mathrm{~kJ} \mathrm{~mol}^{-1}$.) In the present simulations, the pre-exponential factor $\mathrm{A}$ was increased as $E_{a}$ was increased, to maintain a constant value of the rate $\left(0.013 \mathrm{~s}^{-1}\right.$ at $\left.370{ }^{\circ} \mathrm{C}\right)$. Figure 4 shows the mass loss rate with time for PMMA; each frame a.), b.), c.) and d.) shows the result for (21, 50, 100 , and 200) $\mathrm{kW} / \mathrm{m}^{2}$, respectively, while the different curves on each frame show the mass loss for a different value of the activation energy ${ }^{\dagger}$. As illustrated, there exists an external heat flux (e.g., $50 \mathrm{~kW} / \mathrm{m}^{2}$ for which the value of activation energy does not affect the mass loss rate curves (and this heat flux value changes somewhat as the polymer properties, such as the thermal conductivity, and specific heat are varied). At external heat fluxes lower than $50 \mathrm{~kW} / \mathrm{m}^{2}$, lower values of $E_{\mathrm{a}}$ give higher mass loss rates, while at higher heat fluxes, the opposite is true. This is also the case for the average values of MLR: with

\footnotetext{
${ }^{\dagger}$ Note: the random absorption algorithm in ThermaKin was turned off for these calculations to remove the noise in the output and more clearly show the effects of Ea. The results with the random algorithm turned on are qualitatively the same.
} 
the highest value of $E_{a}$, the average MLR are about $0.8,1.01,1.08$ and 1.08 those with the lowest $E_{a}$, for $E H F$, for $\left(21,50,100\right.$, and 200) $\mathrm{kW} / \mathrm{m}^{2}$, respectively. This effect of $E_{a}$ on the MLR is due to changes in the temperature profile with mass loss rate: at low mass loss rate (i.e., low EHF), the temperature gradient is mild, leading to lower surface temperatures and higher sub-surface mass loss, which give larger mass losses at low values of $\mathrm{E}_{\mathrm{a}}$. Conversely, at high mass loss rates (or external heat flux), the high external heat flux leads to high surface temperatures (as shown in Figure 12 and Figure 15) which produce comparatively higher reaction rates at high activation energies.

\section{Thermal Conductivity, $k$}

The effect of changes in the thermal conductivity of the polymer on the mass loss rate as a function of time is shown in Figure 5 for an external heat flux of $21 \mathrm{~kW} / \mathrm{m}^{2}$ ( frame a.) and $100 \mathrm{~kW} / \mathrm{m}^{2}$ (frame b.). The results in Figure 5 were calculated using the nominal property values Table 1, and the five curves in each frame correspond to the five values of the thermal conductivity $(0.1$ to 0.5$) \mathrm{W} \mathrm{m}^{-1} \mathrm{~K}^{-1}$. The MLR $\mathrm{av}_{\mathrm{av}}$ is nearly identical regardless of $k$ (at all values of EHF from $21 \mathrm{~kW} / \mathrm{m}^{2}$ to $200 \mathrm{~kW} / \mathrm{m}^{2}$ ), as expected from Eq. 2, in which $k$ does not appear. The time varying behavior, however, is different. At low EHF, the low conductivity case is thermally thick, while the high conductivity case is thermally thin. At low flux, the time to peak MLR is about half for the high-conductivity case as compared to the low (reflecting the thin behavior); while at high flux, the time to peak MLR is only slightly lower (10\%) for the high value of $k$. (Of course, for the low-flux condition, the time to peak MLR is highly dependent upon the threshold for defining the peak. In the discussion here, reaching a value within a few percent of the maximum is considered to be reaching the "peak" value.) For either low or higher flux, the peak heat release is only a few percent lower for $k=0.1$ compared to $k=0.5$.

\section{$\underline{\text { Absorption Coefficient, } \alpha}$}

Higher transmission of IR through the polymer (lower values of the absorption coefficient $\alpha$ ) creates behavior similar to higher thermal conductivity, namely increased thermally thin behavior. Figure 6 a.) 21 $\mathrm{kW} / \mathrm{m}^{2}$ and b.) $100 \mathrm{~kW} / \mathrm{m}^{2}$ show the effect for $(\alpha=200,400,800,1200,50,000) \mathrm{m}^{-1}$ as different lines in each frame. For all values of $\alpha$, the behavior is thermally thin at low EHF, and thick at higher EHF, and for both values of EHF, the behavior becomes thinner as $\alpha$ decreases. At low flux, the peak MLR is about $13 \%$ lower for surface absorption than for $\alpha=200 \mathrm{~m}^{-1}$, whereas for higher flux, the peak MLR is about $2 \%$ higher for the surface absorption. The average MLR is significantly lower for the low $\alpha$ cases: generally about $20 \%$ lower for $\alpha=200 \mathrm{~m}^{-1}$ (and $10 \%$ for $\alpha=400 \mathrm{~m}^{-1}$ ) as compared to $50000 \mathrm{~m}^{-1}$ for any flux. As with the thermal conductivity, the time to peak MLR is shorter for cases where energy penetrates better into the sample (higher k or lower $\alpha$ ). The very gradual decrease in the MLR at the end of the burning period when $\alpha=200 \mathrm{~m}^{-1}$ is like a result of remaining sample being thinner than the characteristic thermal radiation penetration depth $(1 / \alpha$, or $5 \mathrm{~mm})$, so that not all of the radiant energy is absorbed, decreasing MLR.

\section{Specific Heat, c}

The effects of variations in the specific heat on the time history of the mass loss rate are shown in Figure 7 a.) for $21 \mathrm{~kW} / \mathrm{m}^{2}$ and b.) $100 \mathrm{~kW} / \mathrm{m}^{2}$. The different curves in each frame correspond to $c=(1,2,3,4$, and 5) $\mathrm{kJ} \mathrm{kg}^{-1} \mathrm{~K}^{-1}$. The peak MLR is not much affected by $c$ at low EHF (only about $4 \%$ lower at $c=5$ $\mathrm{kJ} \mathrm{kg}^{-1} \mathrm{~K}^{-1}$ as compared to $c=1 \mathrm{~kJ} \mathrm{~kg}^{-1} \mathrm{~K}^{-1}$ ); while at high EHF, it's about $10 \%$ lower. On the other hand, the average MLR is about $35 \%$ lower (at all values of EHF except $21 \mathrm{~kW} / \mathrm{m}^{2}$, where it's $41 \%$ lower) at $c=5 \mathrm{~kJ} \mathrm{~kg}^{-1} \mathrm{~K}^{-1}$ as compared to $c=1 \mathrm{~kJ} \mathrm{~kg}^{-1} \mathrm{~K}^{-1}$. This effect is due to the contribution of $c$ to $\Delta \mathrm{H}_{\mathrm{g}}$, and the effect of $\Delta \mathrm{H}_{\mathrm{g}}$ on the MLR, as described Eq. 2. (Note that in the present calculations, the 
variation in $c$ from $1 \mathrm{~kJ} \mathrm{~kg}^{-1} \mathrm{~K}^{-1}$ to $5 \mathrm{~kJ} \mathrm{~kg}^{-1} \mathrm{~K}^{-1}$ raises the heat of gasification $\Delta \mathrm{H}_{\mathrm{g}}$ by about a factor of two.) From the average values of MLR calculated from Figure 7, the sensitivity of MLR $_{\mathrm{av}}$ to $\mathrm{c}$ is determined. As described above, $\mathrm{MLR}_{\mathrm{av}} \sim \mathrm{c}^{\mathrm{n}}$ with $\mathrm{n}$ varying from -0.26 to -0.32 , depending upon EHF, while the algebraic relation in Eq. 2 predicts that $n=-0.30$, in good agreement with the detailed numerical results predicted here. As for the time-dependent behavior, higher specific heat affects the MLR in the same way as lower conductivity or higher absorptivity (see Eq. 3), leading to thermally-thick behavior. Results for other heat fluxes $(50,150$, and 200$) \mathrm{kW} / \mathrm{m}^{2}$ show the same trends, and the thermally-thick behavior is accentuated as the flux goes up.

\section{Constant Values of $k$ or $c$}

Both the specific heat and the thermal conductivity of polymers vary with the temperature-which increases significantly as the polymer heats, melts, and decomposes. In the calculations above, the temperature-dependent values were used in the simulations (except when $c$ or $k$ themselves were varied). It is of interest, however, to determine how the results would differ when using a single value of $k$ or $c$, evaluated at the average polymer temperature (between ambient and the decomposition temperature). The MLR as a function of time was calculated using the average value of either $k$ or $c$, and these were normalized by the results using the temperature dependent values. The error imposed by using the average value is not large. For example, for constant $c$ and external heat fluxes of up to $100 \mathrm{~kW} / \mathrm{m}^{2}$, the mass loss rate is at most, $2 \%$ to $5 \%$ higher at some times, than with the temperature dependent value (for all values of $E_{a}$ ), while for high external heat flux $\left(150 \mathrm{~kW} / \mathrm{m}^{2}\right.$ or $\left.200 \mathrm{~kW} / \mathrm{m}^{2}\right)$ using a constant $c$ gives less than $2 \%$ error. For a constant value of $k$, the transient behavior (for example at low flux, or at higher flux and towards the end of the mass-loss period) of the mass loss rate can about $5 \%$ higher than the mass loss rate calculated with a temperature dependent $k$. The steady mass loss rates are generally within $1 \%$, except at high flux, where it can be $1 \%$ high or $2 \%$ low, depending upon $E_{a}$. The average mass loss rate is also not greatly affected by the use of constant $k$ or $c$. For example, for all values of EHF and $\mathrm{E}_{\mathrm{a}}$, using constant $k$ gives average MLRs within $1 \%$ of those using variable $k$, (except the cases of EHF $=200 \mathrm{~kW} / \mathrm{m}^{2}$, and $E_{a}=97 \mathrm{~kJ} \mathrm{kmol}^{-1}$, and $E H F=150 \mathrm{~kW} / \mathrm{m}^{2}$ and $E_{\mathrm{a}}=418 \mathrm{~kJ} \mathrm{kmol}^{-1}$, which yields about a $5 \%$ difference. Using constant $c$ gives average MLRs within $3 \%$ of the results with variable $c$, for all values of Ea, except at $\mathrm{EHF}=200 \mathrm{~kW} / \mathrm{m}^{2}$, for which the results using average $c$ can be $1 \%$ to $10 \%$ low (depending upon $E_{a}$ ). These results (here, for a wider range of $E_{a}$ and incident flux) are consistent with those of Steckler et al. who found close agreement between the time-varying mass loss rate using constant values of $k$ or $c$ (evaluated at a mean temperature) as compared to using temperature-dependent values (for a single case of $40 \mathrm{~kW} / \mathrm{m}^{2}$, surface absorption, and infinite reaction rate).

\subsubsection{Ignition Time}

Simple one-dimensional heat transfer models predict the ignition time for thermally thick or thin materials [29]. The characteristic thermal conduction length $\delta_{\mathrm{t}}$ for thick materials is given by $\delta_{t}=\sqrt{\mathrm{kt} / \rho \mathrm{c}}$, in which in which $\mathrm{t}$ is the exposure time. In the absence of convective and radiative heat losses, thin materials, $S / \delta \leq 1$, have an ignition time given by:

$$
\tau_{i g n}=\rho c S \frac{\left(T_{i g}-T_{0}\right)}{\dot{q}_{e x t}^{\prime \prime}}
$$

and thick materials:

$$
\tau_{\text {ign }}=\frac{\pi}{4} k \rho c \frac{\left(T_{i g}-T_{0}\right)^{2}}{\dot{q}_{\text {ext }}^{2}}
$$


Below, these analytic predictions are compared to the numerical results.

As noted above, the ignition time is calculated from the numerical MLR predictions as the time at which the mass loss rate reaches a critical value $\left(3 \mathrm{~g} \mathrm{~s}^{-1} \mathrm{~m}^{-2}\right)$. The effect of parameter variations on these numerically-determined ignition times are summarized in Figure 8 a.), b.), c.), and d.) and Figure 9, which show the ignition time as a function of $k, c, \alpha, \Delta \mathrm{H}_{\text {reac, }}$ and $\mathrm{S}$, respectively. In each figure there is a grouping of results for each value of the external heat flux, and the different color lines show the variation with $E_{a}$. As indicated, the ignition time is strongly dependent upon the external heat flux, and mildly dependent upon $E_{a}$, except for cases of low EHF $\left(21 \mathrm{~kW} / \mathrm{m}^{2}\right)$, for which $E_{a}$ can make a difference of a factor of three to seven. The variations in magnitude of the parameters $k, c, \alpha$, and $\Delta \mathrm{H}_{\mathrm{g}}$ in the figures is about a factor two above and two below the nominal value for PMMA. Hence, the slopes of the lines give a qualitative estimate of the sensitivity of the ignition time to those parameters. Based on the simple thermal conduction analysis above, for the nominal conditions of Table 1 , the $25.4 \mathrm{~mm}$ thick sample is thermally thick with respect to ignition for $\tau_{\text {ign }}$ less than $7100 \mathrm{~s}$. Hence, for all conditions shown in Figure 8 the sample is thermally thick with respect to ignition, except the lowest flux, at which the behavior can be thin depending upon the parameter value and the activation energy assumed.

\section{Effect of $\dot{q}_{e x t}^{\prime \prime}$}

In Figure 8a.) and b.) for $k$ and $c$, $\tau_{\text {ign }}$ is proportional to $1 / \dot{q}_{\text {ext }}{ }^{2}$, following Eq. 5 above for thick materials (which is the case for these conditions). For varying $\alpha$ (Figure 8c), the results at $\alpha=960 \mathrm{~m}^{-1}$ (the nominal value) also give $\tau_{\text {ign }} \sim 1 / \dot{q}_{\text {ext }}{ }^{2}$, while optically thin material $\left(\alpha=200 \mathrm{~m}^{-1}\right)$ has $\tau_{\text {ign }} \sim 1 / \dot{q}_{\text {ext }}{ }^{1.5}$ and surface absorption shows $\tau_{\text {ign }} \sim 1 / \dot{q}_{\text {ext }}{ }^{2.66}$.

\section{$\underline{k}$}

As shown in Figure 8a, a five-fold increase in thermal conductivity generally causes about a two-fold increase in the ignition time, with a larger effect (3x) at $\mathrm{EHF}=21 \mathrm{~kW} / \mathrm{m}^{2}$ as compared to $(1.5 \mathrm{x})$ at $\mathrm{EHF}=200 \mathrm{~kW} / \mathrm{m}^{2}$. That is, $\tau_{\text {ign }} \sim k^{0.25}$ to $\tau_{\text {ign }} \sim k^{0.67}$, a weaker dependence than the linear behavior expected form Eq. 5, likely resulting from energy penetration dominated by thermal radiation transport for these short times, diluting the effect of thermal conduction.

$\underline{C}$

In Figure 8b, a five-fold increase in the specific heat is shown to result in a five-fold increase in the ignition time for all values of EHF except the lowest (relatively independent of $E_{a}$ ), essentially following the thermally thick prediction $\left(\tau_{\text {ign }} \sim \mathrm{c}^{1}\right)$ in Eq. 5 above. For the low flux conditions EHF $=21 \mathrm{~kW} / \mathrm{m}^{2}$, the material is still thermally thick and $\tau_{\text {ign }} \sim \mathrm{C}^{1.3}$ (and there is a strong dependence on $\mathrm{E}_{\mathrm{a}}$ ).

$\underline{\alpha}$

The absorption coefficient has very little effect on $\tau_{\text {ign }}$ at EHF $=21 \mathrm{~kW} / \mathrm{m}^{2}$. At high EHF (100 to 200) $\mathrm{kW} / \mathrm{m}^{2}$, however, $\tau_{\text {ign }} \sim \alpha^{-0.72}$, so that he $\alpha=200 \mathrm{~m}^{-1}$ case has an ignition time about ten times longer than with $\alpha=50000 \mathrm{~m}^{-1}$, as recently discussed by Jiang et al [30].

$\underline{\Delta H_{\text {reac }}}$

The heat of reaction $\Delta H_{\text {reac }}$ has almost no effect on the ignition time at a given flux, except at very low incident heat fluxes; i.e., very near to the critical heat flux for ignition, where the ignition times are so long that the reaction rates (albeit slow) have an effect on the critical mass flux for ignition.

\section{$\underline{\text { Thickness }}$}


The sample thickness affects the ignition time primarily for thinner samples. As shown in Figure 9 a.) for $\alpha=960 \mathrm{~m}^{-1}$, and b.) $\alpha=50000 \mathrm{~m}^{-1}$, for either value of $\alpha$, and higher values of EHF (100 to 200 ) $\mathrm{kW} / \mathrm{m}^{2}$, the thickness has generally less than a $10 \%$ effect on $\tau_{\text {ign, }}$, as long as the sample is $4 \mathrm{~mm}$ thick or greater. At $2 \mathrm{~mm}$ thickness, the sample is thermally thin, and the dependence of $\tau_{\text {ign }}$ on $\dot{q}_{e x t}^{\prime \prime}$ follows Eq. 4 above for thin materials, for EHF $\geq 50 \mathrm{~kW} / \mathrm{m}^{2}$. For very low EHF $\left(21 \mathrm{~kW} / \mathrm{m}^{2}\right)$, the effects of slow reaction and of surface re-radiation losses affect the ignition time [31], so Eq. 4 and Eq. 5 are not accurate.

\section{Effects of Constant $c$ or $k$}

The ignition time is only moderately affected by using constant values of the thermal conductivity or specific heat of the polymer. A constant value of $c$ yields an ignition time about $10 \%$ shorter than using the temperature-dependent value, for all values of the external heat flux, and this ratio is only affected

slightly by variations in $\mathrm{E}_{\mathrm{a}}$. For constant $k$, the ignition time is again lower, by about $5 \%$, for all external heat fluxes independent of $\mathrm{E}_{\mathrm{a}}$, except at $21 \mathrm{~kW} / \mathrm{m}^{2}$, at which it can be either $6 \%$ higher or lower, depending $\mathrm{E}_{\mathrm{a}}$.

\subsubsection{Comparison of ThermaKin and FDS Results}

All calculations in the present work were performed with both ThermaKin and FDS; however, due to space limitations, only the former are presented in Part 1 (Part 2 includes both). For the nominal values of $k, c, \mathrm{~S}$, and $\Delta \mathrm{H}_{\text {reac }}$, and surface absorption of thermal radiation, the entire time-dependent MLR curves obtained with the two codes are in within $3 \%$ of each other for the range of EHF and $E_{a}$ in Table 1, except the case of $\mathrm{Ea}=837 \mathrm{~kJ} / \mathrm{mol}$ and $\mathrm{EHF}=200 \mathrm{~kW} / \mathrm{m}^{2}$, for which the difference was $6 \%$. Using the nominal value of the absorption coefficient $\left(960 \mathrm{~m}^{-1}\right)$, the general behavior is the same, as evidenced by very close values of average and peak MLR, but the shape of the curves differ slightly. Examination of other solutions with lower values of $\alpha$ indicates that the disagreement becomes worse as $\alpha$ decreases. For the ignition time, when surface absorption is assumed, and over the range of conditions of Table 1 , $\tau_{\text {ign }}$ using FDS is always within $10 \%$ of that from ThermaKin. However, when $\alpha=960 \mathrm{~m}^{-1}$, the FDS prediction is about $46 \%$ higher than the ThermaKin at $\mathrm{EHF}=21 \mathrm{~kW} / \mathrm{m}^{2}$, and $22 \%$ lower at $\mathrm{EHF}=200 \mathrm{~kW} / \mathrm{m}^{2}$. The different treatment of the in-depth absorption of radiation by the two codes is likely responsible for the differences observed, and work is continuing to understand the reasons.

\subsubsection{Conclusions (Part 1)}

The effect of the parameters $\Delta \mathrm{H}_{\text {reac }}, k, \alpha$, and $c$ on $\tau_{\text {ign }}$ and $M L R_{\mathrm{av}}$ are provided in 
Table 2, which gives the power-law dependence of $\tau_{\mathrm{ign}}$ or $\mathrm{MLR}_{\mathrm{av}}$ on each of the parameters. For example, $\tau_{\text {Ign }} \sim \Delta H_{\text {reac }}^{n}$, with $\mathrm{n}=0.02$ at $\mathrm{EHF}=200 \mathrm{~kW} / \mathrm{m}^{2}$, and increasing to $\mathrm{n}=0.14$ at $\mathrm{EHF}=50 \mathrm{~kW} / \mathrm{m}^{2}$; at very low EHF $\left(21 \mathrm{~kW} / \mathrm{m}^{2}\right), \mathrm{n}=1.70$. That is, the ignition time is typically not dependent upon $\Delta \mathrm{H}_{\text {reac }}$, except at low flux. Also given in Table 2 are the expected values of $n$ based on the simple algebraic model in Eq. 2. (Note that the expected dependence of $\tau_{\mathrm{ign}}$ and $\mathrm{MLR}_{\mathrm{av}}$ on $\alpha$ are not given in Table 2. The effect of indepth absorption of radiation shows up as changes to the surface temperature, and hence the radiative heat loss term. While analytic solutions are available [30], they do not have a simple form. ) The ignition time is somewhat dependent upon $k$, increasingly so at lower flux, with $\mathrm{n}=0.28$ or 0.71 at $\mathrm{EHF}=(200$ and 21) $\mathrm{kW} / \mathrm{m}^{2}$, respectively. The ignition time is approximately proportional to $c$, with n close to unity, except at $E H F=21 \mathrm{~kW} / \mathrm{m}^{2}$, for which $\mathrm{n}=1.3$. The effect of $\alpha$ on $\tau_{\text {ign }}$ has the opposite trend, with little dependence at low flux ( $\mathrm{n}=-0.03$ ), but increasing importance at higher flux ( $\mathrm{n}=-0.54$ and -0.77 , at $\mathrm{EHF}=50 \mathrm{~kW} / \mathrm{m}^{2}$ and $200 \mathrm{~kW} / \mathrm{m}^{2}$ ). For comparison, the simple thermal conduction model predicts $\mathrm{n}=1$ for variation of $\tau_{\text {ign }}$ with $k$ and $c$, and $\mathrm{n}=0$ for $\Delta \mathrm{H}_{\text {reac }}$. That is, the dependence calculated here is greater for $\Delta \mathrm{H}_{\text {reac }}$, especially at low flux, about as expected for $c$ (and somewhat greater at low flux), and significantly less for $k$, increasingly so at lower flux. Variation in $\alpha$ can have substantial effect on $\tau_{\text {Ign }}$ at high flux.

As described above, $M_{L R}$ is roughly inversely related to $\Delta H_{\text {reac }}$, with $n=-0.64$ to -0.80 , mildly related to $c$ or $\alpha$, with $\mathrm{n}=-0.27$ to -0.32 , or $\mathrm{n}=0.016$ to -0.14 , respectively, and nearly unrelated to $\mathrm{k}$ with $\mathrm{n}=-0.004$ to -0.010. Expected values of $\mathrm{n}$ for $\mathrm{MLR}_{\mathrm{av}}$ based on a simple heat balance model (Eq. 2) are -0.72, -0.30, and 0 for $\Delta \mathrm{H}_{\text {reac }}, c$, or $k$. Hence, for these three parameters, the simple relationship gives a good estimate of their relative influence on MLR $\mathrm{av}_{\mathrm{av}}$. The effects of in-depth absorption on MLR $\mathrm{R}_{\mathrm{av}}$ can be significant.

Numerical values of the peak MLR and the time to peak MLR were not calculated since these values are highly dependent upon both the threshold for defining the peak (e.g., region of $95 \%$ of peak, etc.), as well as the thermally thick or thin behavior, which switches readily as the physical properties are changed. Instead, the qualitative behavior with respect to these metrics are provided.

Table 3 summarizes the results of the variation in each of the material properties on the mass loss. The influence is characterized by the shape of the mass loss rate (MLR) curve, average MLR, peak MLR, time to peak MLR, and ignition time. In the table, double check marks indicate a large effect on that metric, while single check marks indicate a moderate effect; and a gray single check, even less effect. A blank means no significant effect. Subscripts indicate the conditions (e.g., LF: low flux, HF, high flux) to which the importance is limited. (Note that these qualitative rankings supplement the quantitative results in Table 2.) As shown, the heat of reaction $\Delta H_{\text {reac }}$ is the most important parameter, followed by the thickness $\mathrm{S}$ and specific heat $c$. The absorption coefficient and the conductivity behave similarly, showing an effect on the shape of the MLR, as well as the time to peak at low flux, and on the ignition time for moderate and high fluxes ( $\alpha$ also affects the average MLR at high flux). For the conditions assumed here, the activation energy of the decomposition step is the least important parameter, mildly affecting the shape of the MLR curve at high or low flux, and the average MLR and ignition time at low flux. In future research, it would be of value to examine the effect of the overall reaction rate on the MLR, as well as char layer properties.

For the polymer modeled here, the behavior is often close to intermediate between thermally thick and thin. As a result, varying the material properties often leads to changes in the time-varying MLR curve which are due to switching of the behavior from thick to thin (or visa versa). This has been discussed by Delichatsios et al. [32] in the context of ignition. It is of value to keep this in mind when interpreting the mass loss rate data for materials for which some property change has been made, for example in determining the mode of action of polymer fire retardant additives. 


\subsection{PART 2: Estimation of Heat of Gasification from Cone Calorimeter Mass Loss Data}

\subsubsection{Introduction}

The heat of gasification has a large effect on the mass loss rate. A common method of estimating $\Delta \mathrm{H}_{\mathrm{g}}$ is the method of Tewarson and Pion [4], in which the steady mass loss rate is plotted against the external heat flux, and the inverse of the slope is the effective heat of gasification $\Delta \mathrm{H}_{\mathrm{g}}{ }^{\text {(eff) }}$. As described by Staggs [22], even in the absence of the complicating effects (e.g., changing flame heat feedback, cone radiation trapping by the flame, bubble formation in the polymer and mass transfer limitations to the surface, etc.), the extracted value of $\Delta \mathrm{H}_{\mathrm{g}}{ }^{\text {(eff) }}$ can differ from the actual value substantially (30\% to $40 \%$ ). Hence, it is of value to explore the sensitivity of the results of Staggs for a wider range of material properties.

First, the numerical simulations are used to repeat the analysis of Staggs for his input conditions. This also allows comparison of the analytical prediction of the steady mass loss rate of Staggs with the numerical results calculated using ThermaKin or FDS. Next, the activation energy and absorption coefficient of the PMMA (which were expected to have the largest effect) are varied in a series of calculations, allowing assessment of the effect of these parameters on the inferred effective heat of gasification.

\subsubsection{Comparisons with Analytical Results}

The burning behavior as a function of time of a sample of PMMA exposed to a known radiant heat flux was calculated assuming the material properties and conditions of ref. [22] as listed in Table 1. Staggs' analysis is based on simulations for a mild range of external heat flux $\left(20 \mathrm{~kW} / \mathrm{m}^{2}\right.$ to $\left.70 \mathrm{~kW} / \mathrm{m}^{2}\right)$, and that range is used here. (Staggs includes a convective heat loss term in his calculations $\left(10 \mathrm{~W} \mathrm{~m}^{-2} \mathrm{~K}^{-1}\right)$ so this term is added in the FDS and ThermaKin simulations.) As an overview, Figure 10 shows the predicted MLR (solid lines, left axis) and surface temperature (dotted lines, right axis), for an external heat flux of (20 to 70) $\mathrm{kW} / \mathrm{m}^{2}$. As expected (Eq. 2), the average burning rate and the inverse of the burning time are roughly proportional to the external heat flux. At each value of the external heat flux, the mass loss rate increases from zero at early times, as the energy at the surface penetrates the cold polymer. At longer times, the heat conduction and surface regression rates find an equilibrium which leads to a relatively constant temperature profile through the polymer, and which gives a relatively steady burning rate [22] (for $\mathrm{EHF}<20 \mathrm{~kW} / \mathrm{m}^{2}$ ). The higher EHF conditions have higher surface regression rates, which makes the steady burning rate assumption more accurate (due to more thermally-thick behavior).

The temperature curves in Figure 10 show that at early times, the surface temperature increases as the sample heats, until a relatively constant value is obtained. The apparent rapid surface temperature rise at the very end of the burning period is a result of the limited time step and grid size resolutions in the calculation (so the temperature data are truncated for the last few points). Further refinement of the time stepping and mesh size was deemed unnecessary since that portion of the burning corresponds to a small fraction of the total burning history. As shown in the figure, the higher external heat flux leads to higher surface temperature, about $104 \mathrm{~K}$ higher at $70 \mathrm{~kW} / \mathrm{m}^{2}$ as compared to $20 \mathrm{~kW} / \mathrm{m}^{2}$, an effect which was shown previously in experiments [33] and numerical calculations [5]. To estimate the average surface temperature for each value of external heat flux in Figure 10, the central quarter of the surface temperature-time history was used (which also corresponds to the time very near to the average mass loss rate). 
In order to extract the effective heat of gasification from the mass loss rate data, one plots the steady mass loss rate with the external heat flux, and takes the inverse of the slope as $\Delta \mathrm{H}_{\mathrm{g}}{ }^{\text {(eff) }}$ [4]. In our analysis using the synthetic MLR curves, the calculated mass loss as a function of time is not purely steady, so we used the average burning rate for the time period during which the sample is exposed to the external flux as the steady burning rate; that is, the preheat period during which the sample is heating but not yet losing mass was also used in calculating the average. The logic is that the higher mass loss rate at the end occurs because the sample has been preheated by conduction which occurred earlier, and conceptually, this is offset by the energy input at early times which added to the energy in the sample, even though the mass loss rate was zero or low. The end of the integration period in defining the average was the time at which the MLR decreased to $0.01 \mathrm{~g} \mathrm{~m}^{-2} \mathrm{~s}^{-2}$; this gives nearly identical values of MLR $_{\mathrm{av}}$ as would using a criterion of $3 \mathrm{~g} \mathrm{~s}^{-1} \mathrm{~m}^{-2}$ since the MLR drops very rapidly at the end of the mass loss period for the present simulations. These calculated average values of the mass loss rate are indicated by the short horizontal lines near the center of each curve in Figure 10. As indicated, these average values are very close to the steady burning region (when one exists), and to the inflection point in the MLR versus time curves.

The average values of the mass loss rate are plotted against the external heat flux in Figure 11, for the results from the ThermaKin and FDS numerical models, as well as from the analytical model used by Staggs [22]. As shown, the two numerical models (which use the same input material properties, but different solution techniques) give results with about $1 \%$ of each other (except at the lowest mass loss rates, which differ by $3 \%$ ). Both numerical results are about $8 \%$ higher than the analytic results of Stagg. The reason for the lower mass loss rates in the analytic model results may be related to the estimated surface temperatures, as shown in Figure 12 (right scale, bottom curves). Because the analytic model only has mass loss at the surface (while the numerical models allow mass loss at all positions in the sample), it needs a higher surface temperature for the PMMA to lose the required mass (determined by the energy balance at the surface). This higher surface temperature in the analytical prediction leads to higher radiation heat losses, and lower resulting mass loss rates (less net energy makes it into the polymer).

Another possible reason for the discrepancy between analytical and numerical predictions of the mass loss rates shown in Figure 11 is the use of the average burning rates from Figure 10. An alternative choice would be to use the inflection point in the time-varying mass loss rate shown in Figure 10. Doing so leads to minor changes in the values of the "steady" mass loss rate shown in Figure $11(-17 \%$, - $5 \%$, and $0 \%$ for 20,45 , and $70 \mathrm{~kW} / \mathrm{m}^{2}$, respectively), which leads to an increase in the slope of the mass loss vs. external heat flux curves in Figure 11 of about $4 \%$.

Since the slopes in Figure 11 are in reasonable agreement with each other, the inferred effective heats of gasification $\Delta \mathrm{H}_{\mathrm{g}}{ }^{\text {(eff) }}$ (1/slope) are also in reasonable agreement. Figure 12 shows the effective heat of gasification $\Delta \mathrm{H}_{\mathrm{g}}{ }^{\text {(eff) }}$ and the heat of gasification $\Delta \mathrm{H}_{\mathrm{g}}$ (upper curves, left scale) from the Staggs, FDS, and ThermaKin models (note: $\Delta \mathrm{H}_{\mathrm{g}}{ }^{\text {(eff) }}$ is obtained from the slope of the calculated mass loss vs. EHF curve, while $\Delta \mathrm{H}_{\mathrm{g}}$ is calculated from Eq. 1 above, using the calculated surface temperatures and the assumed $c$ of the PMMA), together with the value of $\Delta \mathrm{H}_{\text {reac }}$ from Table 1. As discussed in ref. [22], value of $\Delta \mathrm{H}_{\mathrm{g}}{ }^{\text {(eff) }}$ extracted from Staggs analytical prediction of the mass loss rate is $1.875 \mathrm{~kJ} / \mathrm{g}$, while that extracted from either the ThermaKin and FDS predictions is $(1.72 \pm 0.02) \mathrm{kJ} / \mathrm{g}$, which is about $8 \%$ lower. Hence, given the differences in the assumptions in the calculations leading to the mass loss curves, this agreement in $\Delta \mathrm{H}_{\mathrm{g}}{ }^{\text {(eff) }}$ is considered acceptable. The FDS- and ThermaKin-calculated values of $\Delta \mathrm{H}_{\mathrm{g}}$ agree within $3 \%$, differing slightly due to the mildly different calculated surface temperatures, also shown in Figure 12.

As a final step in the comparison, we examine the ratio of the value of the heat of gasification extracted from the numerical experiment $\Delta \mathrm{H}_{\mathrm{g}}{ }^{\text {(eff) }}$, with the values of $\Delta \mathrm{H}_{\mathrm{g}}$ which were input into the models. Ideally, the value of $\Delta \mathrm{H}_{\mathrm{g}}{ }^{\text {(eff) }}$ extracted from the mass-loss versus external heat flux curves would reproduce the value of $\Delta \mathrm{H}_{\mathrm{g}}$ which was used as input into the numerical model that generated the mass loss curves. The 
advantage here is that since mass loss curves were calculated, only those physical effects included in the model can affect the value of $\Delta \mathrm{H}_{\mathrm{g}}{ }^{(\text {eff) }}$ obtained. For example, in an actual experiment, as the external heat flux to the polymer is varied by changing the cone heater temperature, variations in the heat flux reaching the polymer surface can be influenced by differences in the heat feedback from the flame (from different flame size and shape), as well as from flame blockage of the radiation from the cone [8]. Since the external heat flux in the numerical calculations is specified exactly, no assumptions are required concerning the constancy of the heat flux from the flame (or radiation absorption by the flame). Hence, one can separate out any differences between the input $\Delta \mathrm{H}_{\mathrm{g}}$ and the extracted $\Delta \mathrm{H}_{\mathrm{g}}{ }^{\text {(eff) }}$ without concern for effects from the flame.

Figure 13 shows the ratio of the effective heat of gasification $\Delta \mathrm{H}_{\mathrm{g}}{ }^{\text {(eff) }}$ (extracted) to the heat of gasification $\Delta \mathrm{H}_{\mathrm{g}}$ (input) for the calculated mass loss rates using the model of Staggs, ThermaKin, and FDS. The two numerical models give results within $1 \%$ of each other, and these are about $6 \%$ lower than the ratio calculated analytically by Staggs. The difference between the analytical and numerical results occurs because, as Figure 11 shows, the Staggs model and the two numerical models predict somewhat different variation of the MLR with EHF. Nonetheless, the basic trends and conclusions are the same: the heat of gasification extracted from the mass loss vs. flux curve will be about $30 \%$ higher than the actual value based on the physical properties of the material, and this difference occurs even the absence of other complications. It should be noted that for accurate numerical prediction of the mass loss rate of several polymers in the NIST gasification device, ThermaKin simulations required the actual physical parameters of the materials, not the effective gasification values obtained through the method described above [12].

As pointed out by Staggs [22], this result has implications for the fire community, which routinely uses cone measurements to obtain effective heats of gasification. The surface temperature variation, caused by the finite rate of chemical reaction of the polymer, leads to errors in the effective heat of gasification extracted from mass loss versus flux curve. The above results were demonstrated, using several different calculation schemes, for a given set of physical parameters of the polymer. It is of interest to determine the extent to which different polymer properties affect this result. The parameters expected to have the biggest effect on the ratio of $\Delta \mathrm{H}_{\mathrm{g}}{ }^{\text {(eff) }}$ to $\Delta \mathrm{H}_{\mathrm{g}}$ are the activation energy of the one-step polymer decomposition reaction $\mathrm{E}_{\mathrm{a}}$, and the absorption of infrared light by the material (which provides in-depth heating), characterized by the absorption coefficient $\alpha$. In the discussion below, we vary these parameters in numerical simulations using ThermaKin, and repeat the above procedure to assess the effect of these changes on the ratio of $\Delta \mathrm{H}_{\mathrm{g}}{ }^{\text {(eff) }}$ to $\Delta \mathrm{H}_{\mathrm{g}}$.

\subsubsection{Parametric Analyses of the Effects of $E_{a}$ and $\alpha$ on $\Delta H_{g}{ }^{(e f f)}$}

The activation energy and the absorption coefficient were varied over a limiting but reasonable range. Values of $E_{a}$ of $(97,209,418$, and 1050) $\mathrm{kJ} / \mathrm{mol}$ were used (while changing the pre-exponential factor A to maintain the overall rate at $0.013 \mathrm{~s}^{-1}$ as described above). The value of $97 \mathrm{~kJ} / \mathrm{mol}$ is that of Staggs [22] and is at the lower end of $E_{a}$ reported; other values in the literature are close to $200 \mathrm{~kJ} / \mathrm{mol}$ [,12], and $1050 \mathrm{~kJ} / \mathrm{mol}$ represents a value approaching infinite reaction rate. For the absorption coefficient, while $930 \mathrm{~m}^{-1}$ is close to recent measurements for black Polycast PMMA [30], some measurements indicate that polyethylene might be close to $400 \mathrm{~m}^{-1}$ [34], and $50000 \mathrm{~m}^{-1}$ is a large value representing surface absorption.

Figure 14 shows the results of the calculations of the average mass loss rate as a function of the external heat flux; each of the three frames shows the results for values of $\alpha$ of $(400,930$, and 50,000$) \mathrm{m}^{-1}$, while the different curves within each frame show the results for the four values of $E_{a}(97,209,418$, and $1050) \mathrm{kJ} / \mathrm{mol}$. As the figures indicate, all of the curves are quite linear, and the surface absorption case $\left(\alpha=50000 \mathrm{~m}^{-1}\right.$ ) shows the largest effect of $E_{a}$, on the magnitude of the slope. From these curves one can 
extract the inverse of the slope to provide the values of the effective heat of gasification $\Delta \mathrm{H}_{\mathrm{g}}{ }^{(\text {eff) }}$, which are shown in Figure 15 (dotted lines, left axis) on the upper part of the frames. As expected from Figure 14, the values of $\Delta \mathrm{H}_{\mathrm{g}}{ }^{\text {(eff) }}$ are quite constant over the range of fluxes tested here, and the variation with $\mathrm{E}_{\mathrm{a}}$ is the largest for the case of surface absorption of the energy.

The numerical results also predict the expected surface temperature as a function of external heat flux, and these are also shown in Figure 15 (dashed curves, bottom part of frames, right axis). The surface absorption case gives the largest variation in $T_{s}$ with the incident flux, and the variation is the largest with the lowest value of $E_{a}$. As in the discussion above, the values of $T_{s}$ allow one to calculate the heat of gasification $\Delta \mathrm{H}_{\mathrm{g}}$ which was essentially input into the numerical calculations, and these also are shown in Figure 15 (solid curves, left axis). Following the calculated surface temperature results (via Eq. 1 above), the variation in $\Delta \mathrm{H}_{\mathrm{g}}$ with the incident flux is largest for the surface absorption case with low activation energy.

The ratio of the $\Delta \mathrm{H}_{\mathrm{g}}{ }^{\text {(eff) }}$ to $\Delta \mathrm{H}_{\mathrm{g}}$, are shown in Figure 16. As indicated, the surface absorption case with low activation energy (as in Figure 13) gives the largest ratio of $\Delta \mathrm{H}_{\mathrm{g}}{ }^{\text {(eff) }}$ to $\Delta \mathrm{H}_{\mathrm{g}}$. The ratio approaches unity as the activation energy increases, and the activation energy becomes less important as the polymer becomes more transparent to infrared light. Thus, the overestimate of $\Delta \mathrm{H}_{\mathrm{g}}{ }^{\text {(eff) }}$ becomes small as $\mathrm{E}_{\mathrm{a}}$ approaches infinity, and is also reduced as the polymer becomes more transparent.

In order for the method of Pion and Tewarson to be accurate for extracting the heat of gasification from the mass loss rate data, the changes in the net heat flux to the polymer must be approximated well by changes in the applied heat flux from the radiant heater. That is, as discussed above, the flame heat transfer to the polymer and the flame (or pyrolysis products) blockage of cone heater radiation must be constant at all applied heat fluxes. These are taken care of in the numerical calculation above, in which the imposed heat flux (purely radiant) is specified, and there is no flame. The net heat flux from the radiant source, however, must also account for heat losses due to re-radiation from the hot polymer surface. Correction for this effect is easily made using the numerical results since the surface temperature is calculated for all conditions, and the surface radiation heat losses are then given by:

$\dot{q}_{r}{ }^{\prime \prime}=\sigma\left(T_{s}{ }^{4}-T_{a}{ }^{4}\right)$ in which $\sigma\left(5.67 \times 10-11 \mathrm{kWm}^{-2}\right)$ is the Stefan-Boltzmann constant, $\mathrm{T}_{\mathrm{s}}$ is the surface temperature, and $\mathrm{T}_{\mathrm{a}}$ is the ambient temperature. It is of interest to determine if the results given in Figure 14 through Figure 16 above are modified if one uses the net heat flux (i.e., the external heat flux minus the energy reradiated from the surface) as the independent variable, instead of the imposed heat flux from the cone as used above [35]. Figure 17 shows the ratio of the $\Delta \mathrm{H}_{\mathrm{g}}{ }^{\text {(eff) }}$ to $\Delta \mathrm{H}_{\mathrm{g}}$ plotted against the net heat flux , for the same three values of the absorption coefficient, and four values of the activation energy of decomposition. As the figure indicates, much of the deviation from unity of the ratio $\Delta \mathrm{H}_{\mathrm{g}}{ }^{\text {(eff) }} / \Delta \mathrm{H}_{\mathrm{g}}$ has been eliminated. Curves for the highest value of $\mathrm{E}_{\mathrm{a}}$ are always very close to unity (around 1.03), and those for the lowest value of $E_{a}$ are only slightly higher (1.06); the results for the most transparent case ( $\alpha=400$ $\mathrm{m}^{-1}$ ) are about a percent higher than the more opaque cases.

For the polymer conditions simulated here, the effective heat of gasification which can be extracted from the mass loss rate data at different incident heat fluxes is only $2 \%$ to $6 \%$ higher than the true values if the heat flux is corrected for the radiant heat losses from the polymer surface. Nonetheless, in practice, one usually does not know the polymer surface temperature a priori-especially how it changes with heat flux, so this is a difficult correction to make. The advantage here is that since all of the mass loss rates were calculated, we can estimate the radiant heat losses directly to assess the importance of this parameter on the result. 
Higher values of the activation energy and lower values of the absorption coefficient lead to better agreement between $\Delta \mathrm{H}_{\mathrm{g}}{ }^{\text {(eff) }}$ and $\Delta \mathrm{H}_{\mathrm{g}}$, with the ratio $\Delta \mathrm{H}_{\mathrm{g}}{ }^{\text {(eff) }} / \Delta \mathrm{H}_{\mathrm{g}} 1.04$ to 1.14 for $\alpha=400 \mathrm{~m}^{-1}$ and 1.03 to 1.22 for $\alpha=50000 \mathrm{~m}^{-1}$, for EHF of $20 \mathrm{~kW} / \mathrm{m}^{2}$ to $70 \mathrm{~kW} / \mathrm{m}^{2}$. Correcting the external heat flux for the surface re-radiation (yielding a net external heat flux) lead to values of $\Delta \mathrm{H}_{\mathrm{g}}{ }^{\text {(eff) }} / \Delta \mathrm{H}_{\mathrm{g}}$ of 1.04 to $1.07 \alpha=400$ $\mathrm{m}^{-1}$ and 1.02 to 1.04 for $\alpha=50000 \mathrm{~m}^{-1}$. A method for estimating the pyrolysis temperature of charring materials has recently been reported [36]. If a similar analysis could be developed for thermoplastics which would predict the surface temperature as a function of EHF, it could improve estimates of $\Delta \mathrm{H}_{\mathrm{g}}$ (eff). Interestingly, the surface temperature measurements of Rhodes [37] for this material for a range of EHF show an increase in the surface temperature from about $635 \mathrm{~K}$ at $20 \mathrm{~kW} / \mathrm{m}^{2}$ to $650 \mathrm{~K}$ at $60 \mathrm{~kW} / \mathrm{m}^{2}$, which from the middle frame of Figure 15, implies an activation energy between $209 \mathrm{~kJ} \mathrm{~mol}^{-1}$ and $418 \mathrm{~kJ} \mathrm{~mol}^{-1}$.

\subsubsection{Conclusions (Part 2)}

The influence of sub-surface reaction on the effective heat of gasification, $\Delta \mathrm{H}_{\mathrm{g}}{ }^{\text {(eff) }}$, inferred from the mass loss vs. flux data was determined. Previous analytical predictions of mass loss rate of PMMA exposed to external heat fluxes of $20 \mathrm{~kW} / \mathrm{m}^{2}$ to $70 \mathrm{~kW} / \mathrm{m}^{2}$, were validated using ThermaKin and FDS simulations. These two codes predicted effective heat of gasification, $\Delta \mathrm{H}_{\mathrm{g}}{ }^{\text {(eff) }}$ within about $0.06 \%$ of each other, and these were about $6 \%$ smaller than those of Staggs. In the ThermaKin simulations, this lead to a discrepancy between $\Delta \mathrm{H}_{\mathrm{g}}{ }^{\text {(eff) }}$ (inferred) and $\Delta \mathrm{H}_{\mathrm{g}}$ (input) of $20 \%$ to $30 \%$, which was somewhat lower than $30 \%$ to $40 \%$ value estimated analytically by Staggs. Using ThermaKin, that analyses were extended to other conditions of PMMA properties.

Higher values of the activation energy and lower values of the absorption coefficient tended to drive the

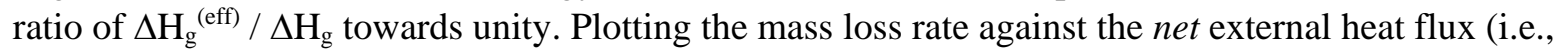
correcting for differing surface re-radiation due to varying surface temperature with imposed heat flux) makes $\Delta \mathrm{H}_{\mathrm{g}}{ }^{\text {(eff) }}$ and $\Delta \mathrm{H}_{\mathrm{g}}$ within $2 \%$ to $6 \%$ of each other. Hence, devising a means to estimate $\mathrm{T}_{\mathrm{s}}$ could improve somewhat the utility of the method of Tewarson and Pion to estimate $\Delta \mathrm{H}_{\mathrm{g}}$. In future work, it would be interesting to numerically investigate the influence of other parameters, such as char layer formation, on the ratio of $\Delta \mathrm{H}_{\mathrm{g}}{ }^{\text {(eff) }}$ to $\Delta \mathrm{H}_{\mathrm{g}}$.

\section{CONCLUSIONS}

The time varying mass loss rate for PMMA with a range of physical properties has been predicted numerically. The variations in the average mass loss rate due to changes in the heat of reaction, specific heat, and thermal conductivity are well predicted by the simple algebraic relations based on energy balance at the surface. The ignition time is influenced by heat of reaction and the specific heat as expected based on simple thermal conduction models, although their effect is somewhat greater than expected at low flux. The variation in the ignition time with changes to the thermal conductivity is about one third the expected value based simple theory, most likely due to the competing effect of in-depth absorption as a mechanism for heat transfer into the sample. The material's absorption coefficient for IR can influence the $M_{L} R_{a v}$ significantly, and the ignition time at substantially.

An insight gleaned from Part I of the present work is that while most of the properties studied here ( $\dot{q}_{e x t}^{\prime \prime}$, $k, c, \alpha, \Delta \mathrm{H}_{\text {reac }}$, and $\mathrm{S}$, ) have varying effect on the mass loss rate and ignition time, they all affect the thermal thickness of the material and hence, have the potential to switch the behavior from thermally thick to thermally thin, and consequently change the MLR curves both qualitatively and quantatively. When making changes to a polymer to promote fire-safe behavior, care should be taken in interpreting experimental data to insure that the material property being changed is not just changing the thermal 
thickness of the material. The heat of reaction is the most important parameter of those examined, and needs to be determined most accurately.

In Part II, the predictions of Staggs with regard to the differences between the actual heat of gasification of a material and that extracted from experimental mass loss vs. heat flux data was verified. For the conditions simulated here, varying the polymer properties to include more optically transparent materials, and those with higher activation energy of decomposition made the discrepancy between the two numbers less, and correcting for the surface re-radiation losses virtually eliminated the discrepancy.

\section{ACKNOWLEDGEMENTS}

The author is grateful to Kevin McGrattan and Simo Hostikka for aid in using FDS, and Stanislav Stoliarov and Richard Lyon for aid in using ThermaKin. Takashi Kashiwagi at NIST originally suggested this line of research, and helpful conversations with him contributed throughout. 


\section{REFERENCES}

[1] Standard test method for heat and visible smoke release rates for materials and products using an oxygen consumption calorimeter. 2008;(ASTM E 1354-08a):1-31.

[2] Standard test methods for measurement of synthetic polymer material flammability using a fire propagation apparatus. 2006;(ASTM E2058-06):

[3] Austin, PJ, Buch, RR, and Kashiwagi, T. Gasification of silicone fluids under external thermal radiation part I. Gasification rate and global heat of gasification. Fire and Materials 1998;22:22137.

[4] Tewarson, A and Pion, RF. Flammability of Plastics .1. Burning Intensity. Combustion and Flame 1976;26:85-103.

[5] Vovelle, C, Delfau, JL, Reuillon, M, Bransier, J, and Laraqui, N. Experimental and numerical study of the thermal degradation of PMMA. Combustion Science and Technology 1987;53:187201.

[6] Steckler, KD, Kashiwagi, T, Baum, HR, and Kanemaru, K. Analytic model for transient gasification of non-charring thermoplastic materials London: Elsevier Applied Science; 1991. p. 895-904.

[7] Hopkins, D and Quintiere, JG. Material fire properties and predictions for thermoplastics. Fire Safety Journal 1996;26:241-68.

[8] Rhodes, BT and Quintiere, JG. Burning rate and flame heat flux for PMMA in a cone calorimeter. Fire Safety Journal 1996;26:221-40.

[9] Staggs, JEJ and Whiteley, RH. Modelling the combustion of solid-phase fuels in cone calorimeter experiments. Fire and Materials 1999;23:63-69.

[10] Nicolette, VV, Erickson, KL, and Vembe, BE. Numerical simulation of decomposition and combustion of organic materials. In: Proceedings of Interflam 2004, 10th InternationalConference on Fire Science and Engineering London: Interscience Communications Ltd. 2004.

[11] Lautenberger, C and Fernandez-Pello, AC. Approximate analytical solutions for the transient mass loss rate and piloted ignition time of a radiatively heated solid in the high heat flux limit. In: Fire Safety Science-Proceedings of the Eighth International Symposium: International Association for Fire Safety Science; 2005. p. 445-56.

[12] Stoliarov, SI, Crowley, S, Lyon, RE, and Linteris, GT. Prediction of the burning rates of noncharring polymers. Combust Flame 2009;156:1068-83.

[13] Kim, E, Lautenberger, C, and Dembsey, NA. Property estimation for pyrolysis modeling applied to polyester FRP composites with different glass contents. In: 11th International Conference and Exhibition London: Interscience; 2009. p. 87-102.

[14] Paul, K. unpublished data, RAPA Technology, Shawbury, England, as cited in: SFPE Handbook, Babrauskus, Chapter 3-1. 2002; 
[15] Hirschler, MM. Heat release from plastics. In: Heat release in fires Amsterdam: Elsevier; 1992. p. 375-422.

[16] Schartel, B, Bartholmai, M, and Knoll, U. Some comments on the use of cone calorimeter data. Polymer Degradation and Stability 2005;88:540-47.

[17] Schartel, B and Hull, TR. Development of fire-retarded materials - Interpretation of cone calorimeter data. Fire and Materials 2007;31:327-54.

[18] Stoliarov, SI, Safronava, N, and Lyon, RE. The effect of variation in polymer properties on the rate of burning. Fire and Materials 2009;submitted:

[19] McGrattan, KB, Klein, B, Hostikka, S, and Floyd, J. Fire dynamics simulator (version 5) user's guide. 2007;NIST Special Publication 1019-5:1-176.

[20] Stoliarov, SI and Lyon, RE. Thermo-kinetic model of burning. 2008;Federal Aviation Administration Technical Note DOT/FAA/AR-TN08/17:1-32.

[21] Stoliarov, SI and Lyon, RE. Thermo-Kinetic model of burning for pyrolyzing materials. In: Proceedings of the Ninth International Symposium on Fire Safety Science London: Interscience Communications, Ltd.; 2008. p. 1141-52.

[22] Staggs, JEJ. The heat of gasification of polymers. Fire Safety Journal 2004;39:711-20.

[23] Panagiotou, T and Quintiere, JG. Generalizing Flammability of Materials. In: Interflam 2004 London: Interscience Communications Ltd.; 2004. p. 895-905.

[24] Linteris, GT, Gewuerz, L, McGrattan, KB, and Forney, GP. Modeling Solid Sample Burning with FDS. 2004;NISTIR 7178:36 p.

[25] Stoliarov, SI and Walters, RN. Determination of the heats of gasification of polymers using differential scanning calorimetry. Polymer Degradation and Stability 2008;93:422-27.

[26] Stoliarov, SI, Walters, RN, and Lyon, RE. Determination of heats of gasification of polymers using differential scanning calorimetry. 2007;

[27] Tewarson, A. Generation of heat and chemical compounds in fires. In: SFPE Handbook of Fire Protection Engineering Quincy, MA: National Fire Protection Association; 1995. p. 3-53.

[28] Quintiere, JG and Iqbal, N. An approximate integral model for the burning rate of a thermoplastic-like material. Fire and Materials 1994;18:89-98.

[29] Drysdale, D. An introduction to fire dynamics. Chichester, England: John Wiley and Sons; 1998.

[30] Jiang, FH, de Ris, JL, and Khan, MM. Absorption of thermal energy in PMMA by in-depth radiation. Fire Safety Journal 2009;44:106-12.

[31] Mikkola, E and Wichman, IS. On the Thermal Ignition of Combustible Materials. Fire and Materials 1989;14:87-96. 
[32] Delichatsios, MA, Panagiotou, T, and Kiley, F. The Use of Time to Ignition Data for Characterizing the Thermal Inertia and the Minimum (Critical) Heat-Flux for Ignition Or Pyrolysis. Combustion and Flame 1991;84:323-32.

[33] Kashiwagi, T and Ohlemiller, TJ. A study of oxygen effects on flaming transient gasification of PMMA and PE during thermal irradiation. Proceedings of the Combustion Institute 1982;19:81523.

[34] Linteris, GT. Absoprtion of thermal radiation by burning polymers. Fire Safety Journal 2009;to be submitted:1-30.

[35] Janssens, ML. Personal communication. 2008;

[36] Park, WC, Atreya, A, and Baum, HR. Determination of pyrolysis temperature for charring materials. Proceedings of the Combustion Institute 2009;32:2471-79.

[37] Rhodes, BT. Burning rate and flame heat flux for PMMA in the cone calorimeter. 2009;NISTGCR-95-664:1-118. 
Table 1- PMMA model input parameters.

\begin{tabular}{|c|c|c|c|c|c|}
\hline \multirow[b]{2}{*}{ OParameter } & \multirow[b]{2}{*}{$\underline{\text { Units }}$} & \multicolumn{2}{|c|}{$\begin{array}{c}\text { Part } 1 \\
\text { Parametric Analysis }\end{array}$} & \multicolumn{2}{|c|}{$\begin{array}{c}\text { Part 2 } \\
\Delta H_{\mathrm{g}}{ }^{\text {(eff) }} \text { Determination }\end{array}$} \\
\hline & & $\begin{array}{l}\text { Nominal } \\
\text { Value }\end{array}$ & Range & $\begin{array}{l}\text { Nominal } \\
\text { Value }\end{array}$ & Range \\
\hline \multicolumn{6}{|l|}{ Material Bulk Properties: } \\
\hline Thermal Conductivity & $\mathrm{W} \mathrm{m} \mathrm{m}^{-1} \mathrm{~K}^{-1}$ & 0.235 & 0.1 to 0.5 & 0.22 & \\
\hline Specific Heat & $\mathrm{kJ} \mathrm{kg}^{-1} \mathrm{~K}^{-1}$ & 2.22 & 1 to 5 & 1.42 & \\
\hline Absorption Coefficient & $\mathrm{m}^{-1}$ & 960 & 200 to 50000 & $\infty$ & 400 to 50000 \\
\hline \multicolumn{6}{|l|}{$\begin{array}{l}\text { Material Decomposition } \\
\text { Properties: }\end{array}$} \\
\hline Heat of Reaction & $\mathrm{kJ} \mathrm{kg}^{-1}$ & 2000 & 1000 to 5000 & 840 & \\
\hline Activation Energy & $\mathrm{kJ} \mathrm{mol}^{-1}$ & 209 & 97 to 837 & 97 & 97 to 1050 \\
\hline Pre-exponential & $S^{-1}$ & $1.29 \times 10^{15}$ & $\begin{array}{c}1.02 \times 10^{6} \\
\text { to } 1.25 \times 10^{66}\end{array}$ & $1.02 \times 10^{6}$ & $\begin{array}{l}1.02 \times 10^{6} \\
\text { to } 1.24 \times 10^{83}\end{array}$ \\
\hline \multicolumn{6}{|l|}{ Experiment Properties: } \\
\hline Incident Heat Flux & $\mathrm{kW} \mathrm{m} \mathrm{m}^{-2}$ & 50 & 21 to 200 & & 20 to 70 \\
\hline Thickness & $\mathrm{mm}$ & 25.4 & 2 to 32 & 15 & \\
\hline \multicolumn{6}{|l|}{ Not varied: } \\
\hline Density & $\mathrm{kg} \mathrm{m}^{-3}$ & 1190 & & 1190 & \\
\hline Ambient Temperature & $\mathrm{K}$ & 293 & & 293 & \\
\hline $\begin{array}{l}\text { Convective Heat Transfer } \\
\text { from Surface }\end{array}$ & $\mathrm{W} \mathrm{m} \mathrm{m}^{-2} \mathrm{~K}^{-1}$ & 0 & & 10 & \\
\hline Surface Emissivity & & 0.95 & & 1 & \\
\hline
\end{tabular}


Table 2 - Power-law $\left(y=A x^{n}\right)$ fit parameter $n$ for $y=$ ignition time, $\tau_{\text {ign }}$ or average mass loss rate MLR $_{\mathrm{av}}$, with $\mathbf{x}=\mathbf{k}, \mathrm{c}, \boldsymbol{\alpha}$, or $\Delta \mathbf{H}_{\text {reac. }}$

\begin{tabular}{|c|c|c|c|c|c|c|c|c|}
\hline \multirow[b]{2}{*}{ Parameter: } & \multicolumn{8}{|c|}{ Power-Law Parameter n } \\
\hline & \multicolumn{2}{|c|}{$\Delta \mathbf{H}_{\text {reac }}$} & \multicolumn{2}{|r|}{ c } & \multicolumn{2}{|c|}{$\alpha *$} & \multicolumn{2}{|c|}{$\mathbf{k}$} \\
\hline Flux & $\tau_{\text {ign }}$ & $\mathrm{MLR}_{\mathrm{av}}$ & $\tau_{\text {ign }}$ & $\operatorname{MLR}_{\mathrm{av}}$ & $\tau_{\text {ign }}$ & $\mathrm{MLR}_{\mathrm{av}}$ & $\tau_{\text {ign }}$ & $\mathrm{MLR}_{\mathrm{av}}$ \\
\hline 21 & 1.70 & -0.72 & 1.30 & -0.32 & -0.03 & 0.016 & 0.71 & -0.005 \\
\hline 50 & 0.140 & -0.745 & 1.00 & -0.26 & -0.54 & -0.079 & 0.54 & -0.004 \\
\hline 100 & 0.046 & -0.69 & 0.91 & -0.26 & -0.67 & -0.12 & 0.33 & -0.010 \\
\hline 150 & 0.044 & -0.64 & 1.00 & -0.26 & -0.75 & -0.14 & 0.29 & -0.009 \\
\hline 200 & 0.020 & -0.80 & 0.97 & -0.27 & -0.77 & -0.12 & 0.28 & -0.010 \\
\hline \multicolumn{9}{|c|}{ Expected value } \\
\hline & 0.0 & -0.72 & 1.0 & -0.30 & n.a. & n.a. & 1.0 & 0.0 \\
\hline
\end{tabular}

* the data range for $\alpha$ was limited to $200 \mathrm{~m}^{-1}$ to $1200 \mathrm{~m}^{-1}$ to give a good fit. n.a. not available.

Table 3 - Influence of model input parameters on mass loss rate and ignition time.

\begin{tabular}{|c|c|c|c|c|c|}
\hline arameter & \multicolumn{4}{|c|}{ Mass Loss Rate (MLR) } & Ignition Tim \\
\hline & Shape & Average & peak & tpeak & \\
\hline$\Delta H_{\text {reac }}$ & $\checkmark \checkmark$ & $\checkmark \sqrt{ }$ & $\checkmark \checkmark$ & $\checkmark \checkmark$ & $\checkmark_{\mathrm{LF}}$ \\
\hline $\mathrm{S}$ & $\checkmark \checkmark$ & $\widehat{V}_{\mathrm{HF}_{\mathrm{L} \alpha}}$ & & $\checkmark \checkmark$ & $\sqrt{\mathrm{LF}}$ \\
\hline C & $\checkmark$ & $\checkmark$ & $\sqrt{ } \mathrm{HF}$ & $\sqrt{\mathrm{LF}}$ & $\checkmark \checkmark$ \\
\hline$\alpha$ & $\checkmark$ & $\sqrt{\mathrm{HF}}$ & & $\checkmark_{\mathrm{LF}}$ & $\checkmark_{\text {not LF }}$ \\
\hline k & $\checkmark$ & & & $\checkmark_{\mathrm{LF}}$ & $\checkmark$ \\
\hline$E_{a}$ & $\sqrt{ } \mathrm{HF}_{1}$ & $\checkmark_{\text {LF }}$ & & & $\checkmark_{\text {LF }}$ \\
\hline
\end{tabular}




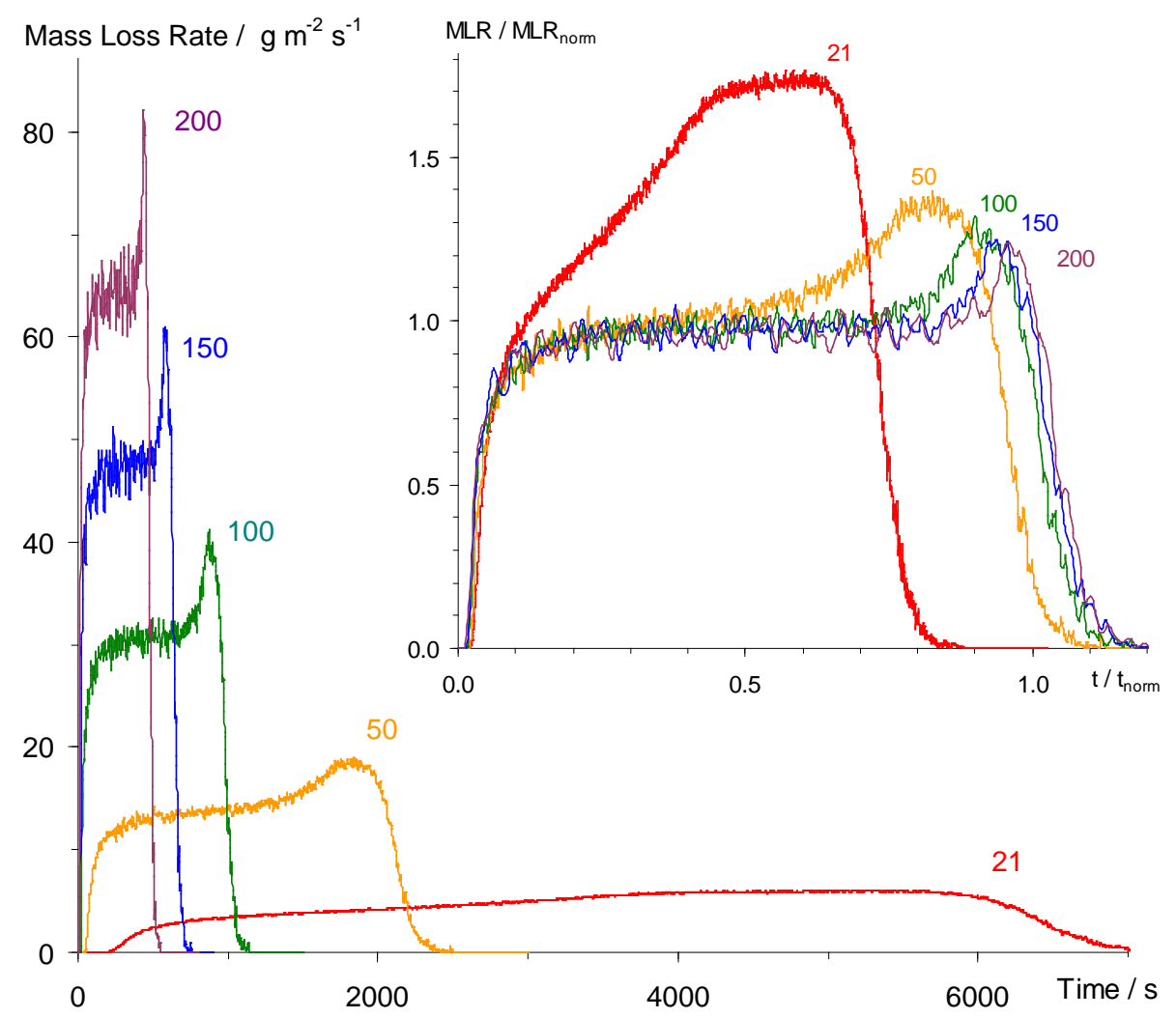

Figure 1 - Calculated mass loss rate of $25.4 \mathrm{~mm}$ thick black PMMA subjected to incident radiant fluxes of $(21,50,100,150$, and 200$) \mathrm{kW} / \mathrm{m}^{2}$. (Inset shows same data with MLR and $t$ normalized.) 

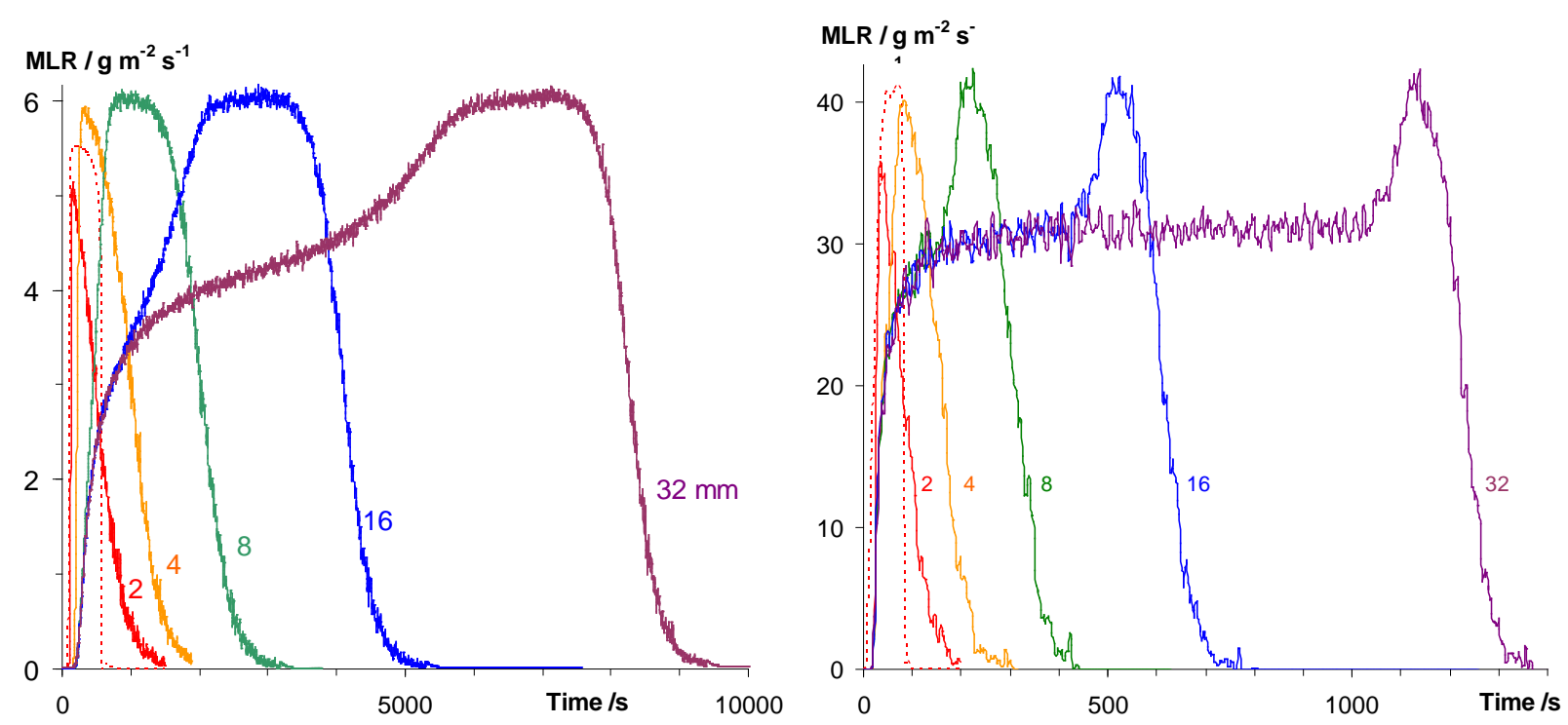

Figure 2 - Mass loss rate versus time for PMMA at external heat fluxes of a.) $21 \mathrm{~kW} / \mathrm{m}^{2}$ and b.) $100 \mathrm{~kW} / \mathrm{m}^{2}$. Different curves on each frame show the effect of thickness of $(2,4,8,16$, and 32) $\mathrm{mm}$. Dotted line shows the result for $2 \mathrm{~mm}$ case with surface absorption.
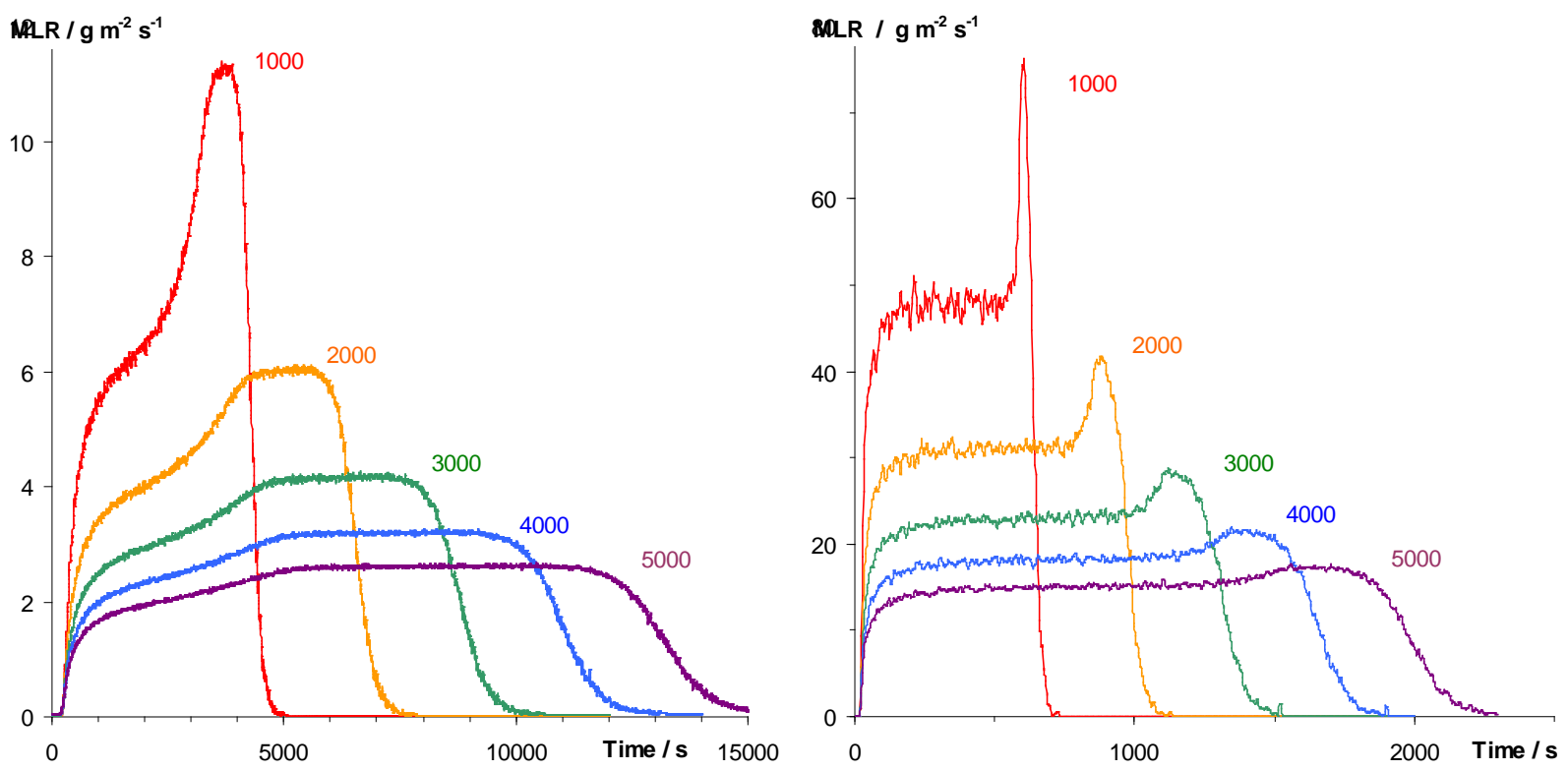

Figure 3 - Mass loss rate versus time for PMMA at external heat fluxes of (21and 100) $\mathrm{kW} / \mathrm{m}^{2}$, frames a. ) and b.), respectively, with a value of $E_{a}=209 \mathrm{~kJ} / \mathrm{mol}$. Different curves on each frame show the effect of $\Delta H_{\text {reac }}=$ $(1000,2000,3000,4000$, and 5000$) \mathrm{kJ} \mathrm{kg}^{-1}$. 


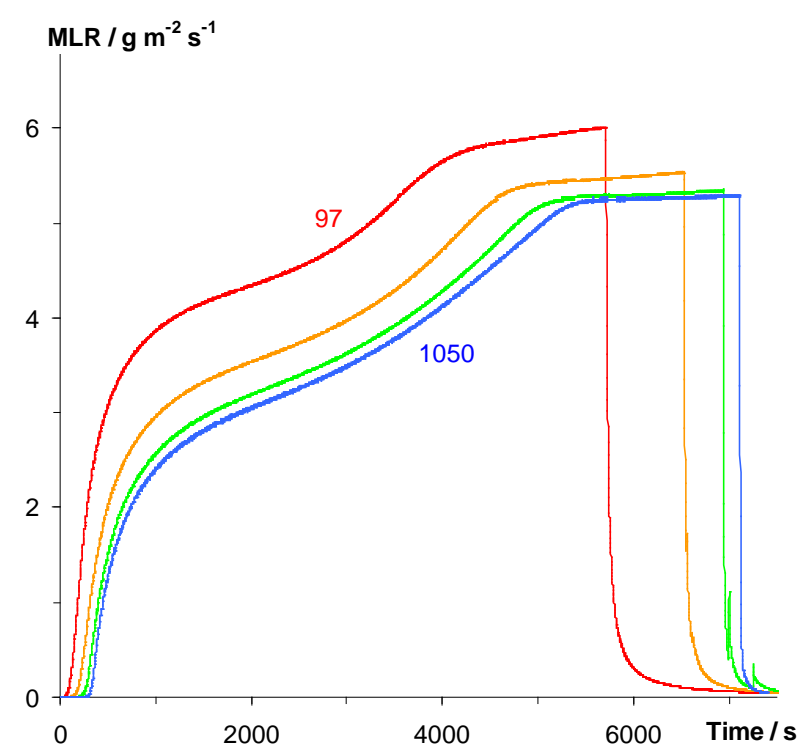

a.)

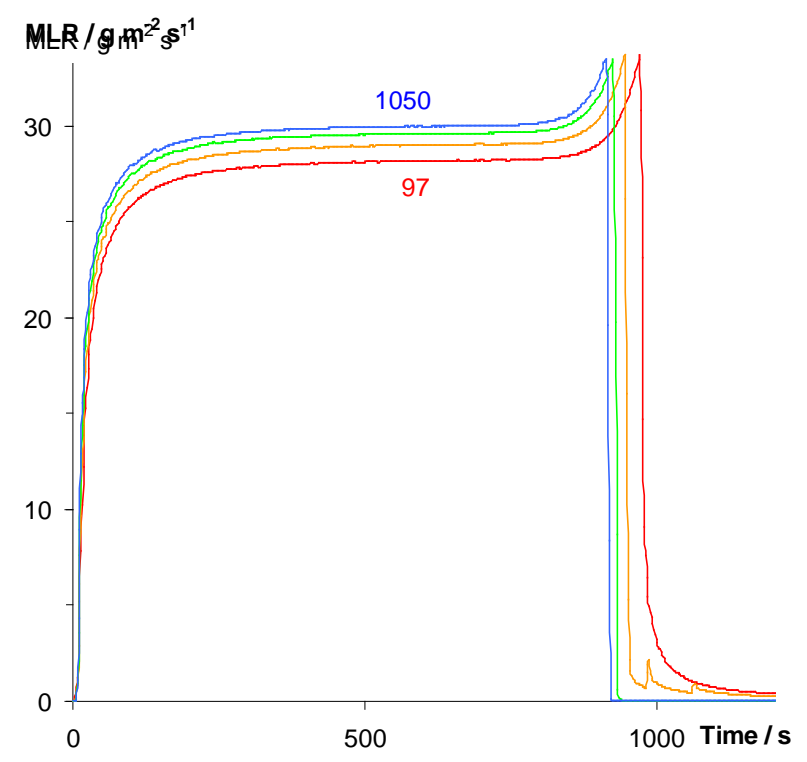

c.)

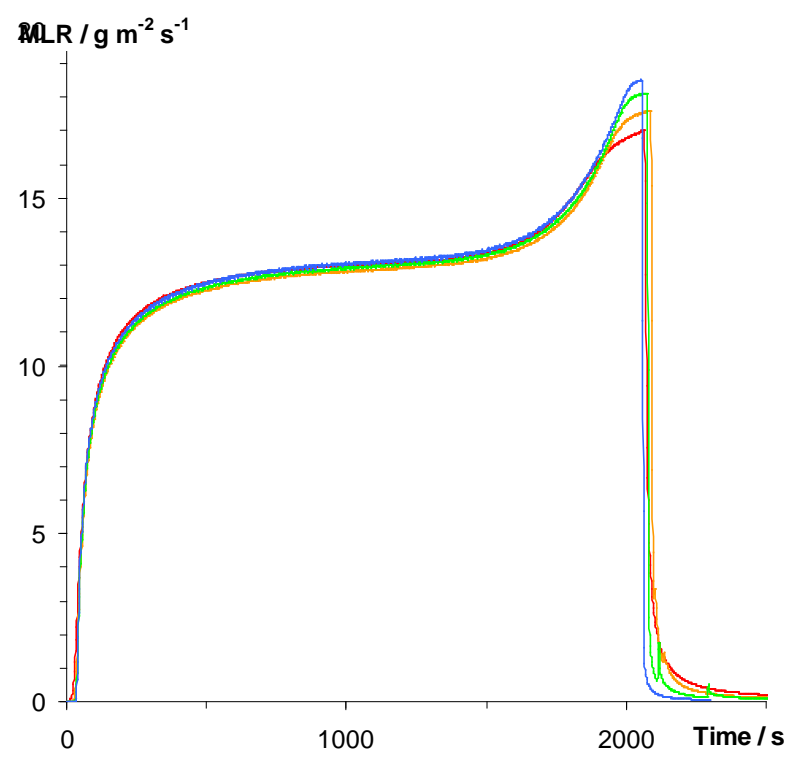

b.)

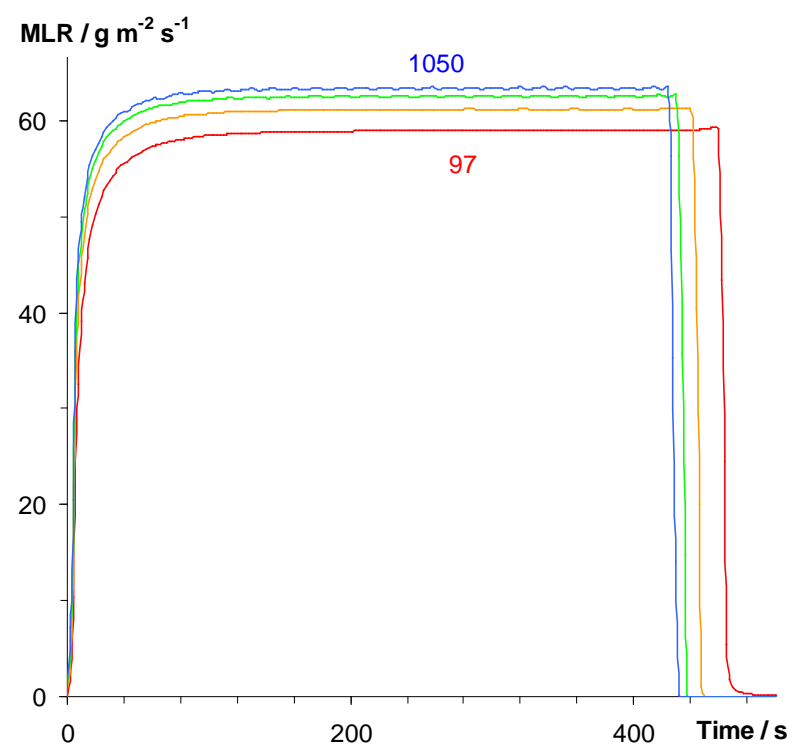

d.)

Figure 4 - Mass loss rate versus time for PMMA at external heat fluxes of $(21,50,100$, and 200$) \mathrm{kW} / \mathrm{m}^{2}$, frames a. ) through $d$.), respectively. Different curves on each frame show the effect of $E_{a}=(97,209,418$, and 1050) $\mathrm{kJ} / \mathrm{mol}$. 

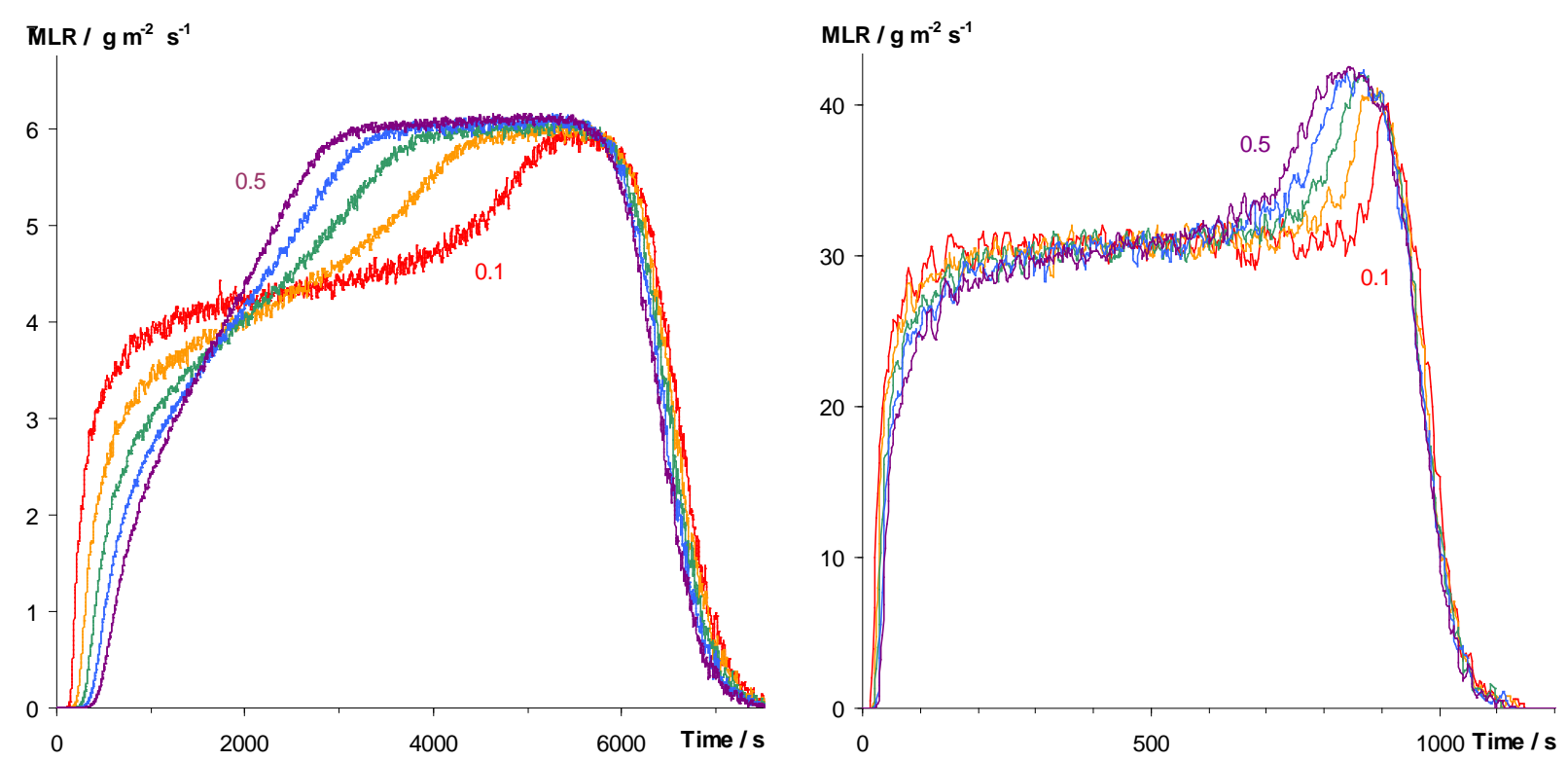

Figure 5 - Mass loss rate versus time for PMMA at external heat fluxes of (21and 100) $\mathrm{kW} / \mathrm{m}^{2}$, frames a. ) and b.), respectively, with a value of $E_{a}=209 \mathrm{~kJ} / \mathrm{mol}$. Different curves on each frame show the effect of $k=(0.1,0.2$, $0.3,0.4$, and 0.5 ) $\mathrm{W} \mathrm{m}^{-1} \mathrm{~K}^{-1}$.
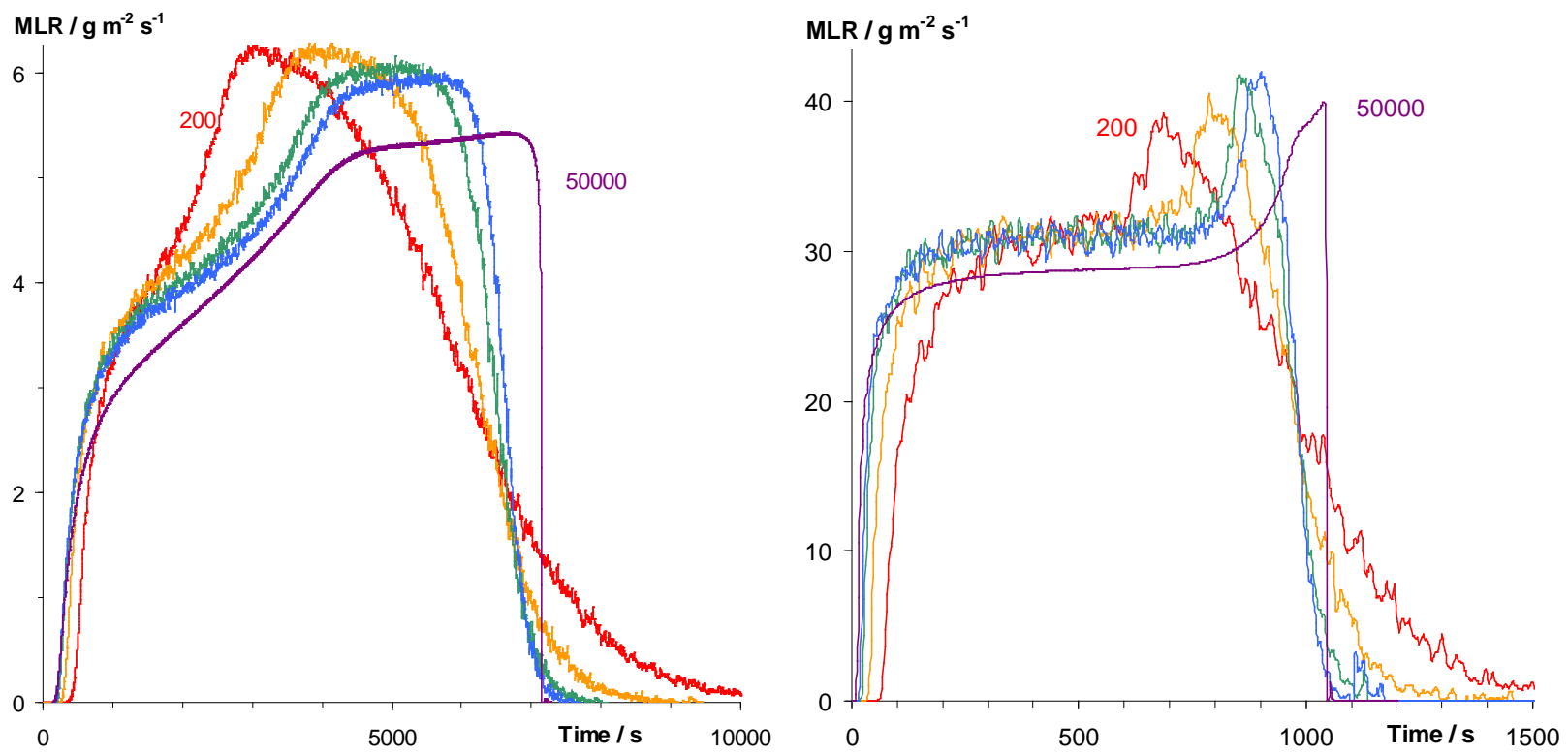

Figure 6 - Mass loss rate versus time for PMMA at external heat fluxes of (21and 100) $\mathrm{kW} / \mathrm{m}^{2}$, frames a. ) and b.), respectively, with a value of $E_{a}=209 \mathrm{~kJ} / \mathrm{mol}$. Different curves on each frame show the effect of alpha $=$ $(200,400,800,1200$, and 50000$) \mathrm{m}^{-1}$. 

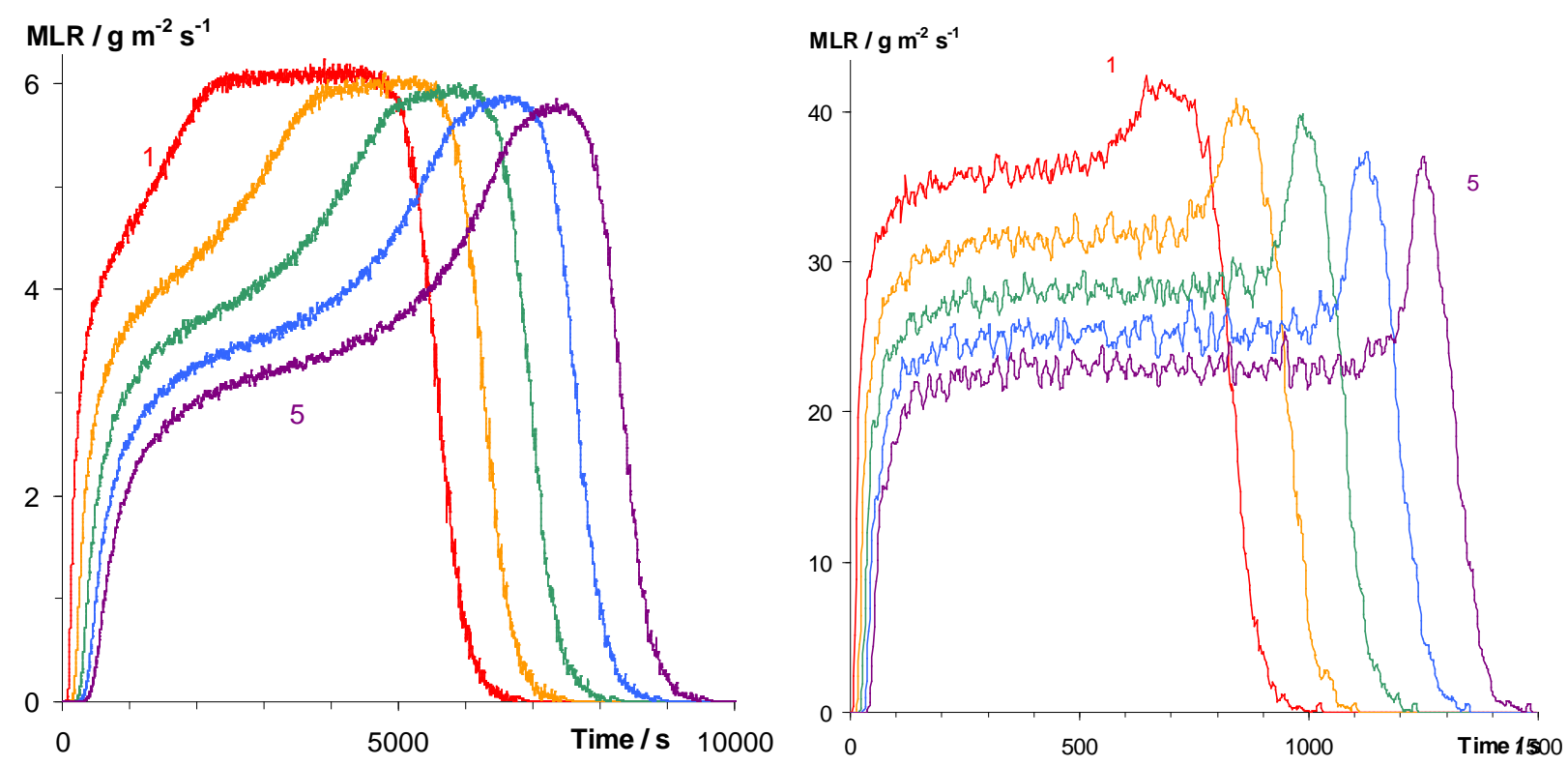

Figure 7 - Mass loss rate versus time for PMMA at external heat fluxes of a.) $21 \mathrm{~kW} / \mathrm{m}^{2}$ and $\mathbf{b}$.) $100 \mathrm{~kW} / \mathrm{m}^{2}$, with $E_{a}=209 \mathrm{~kJ} / \mathrm{mol}$. Different curves on each frame show the effect of $c=\left(1,2,3,4\right.$, and 5) $\mathrm{kJ} \mathrm{kg}^{-1} \mathrm{~K}^{-1} \cdot \mathrm{m}^{-1}$. 

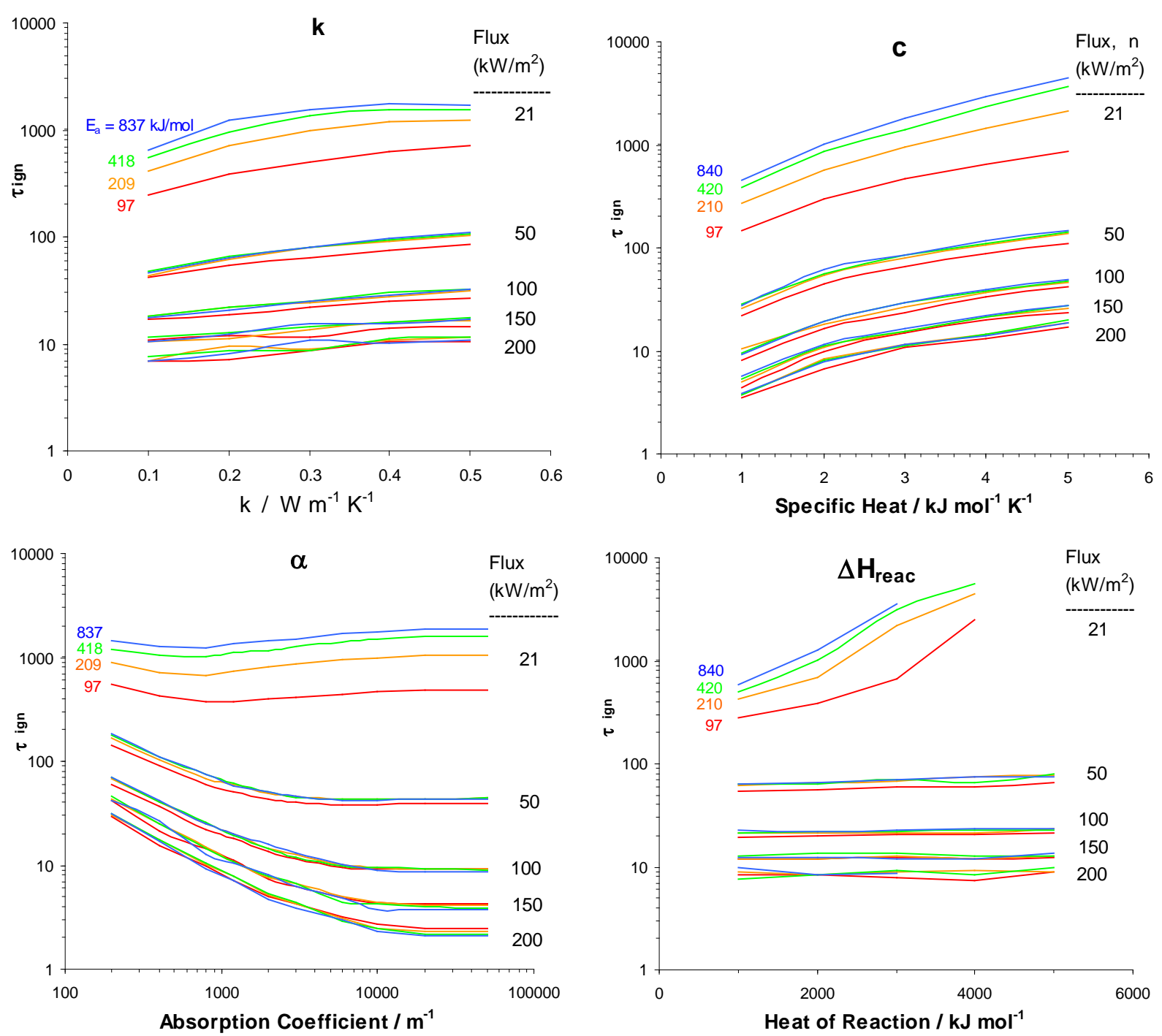

Figure 8 - Ignition time variation for values of the external heat flux of $(21,50,100,150$, and 200$) \mathrm{kW} / \mathrm{m}^{2}$, and values of the PMMA decomposition activation energy of $(97,209,518$, and 1050) $\mathrm{kJ} / \mathrm{mol}$ : a.) thermal conductivity, $k$; b.) specific heat, $c$; $c$.) absorption coefficient, $\alpha$; and d.) heat of reaction, $\Delta \mathbf{H}_{\text {reac. }}$ 

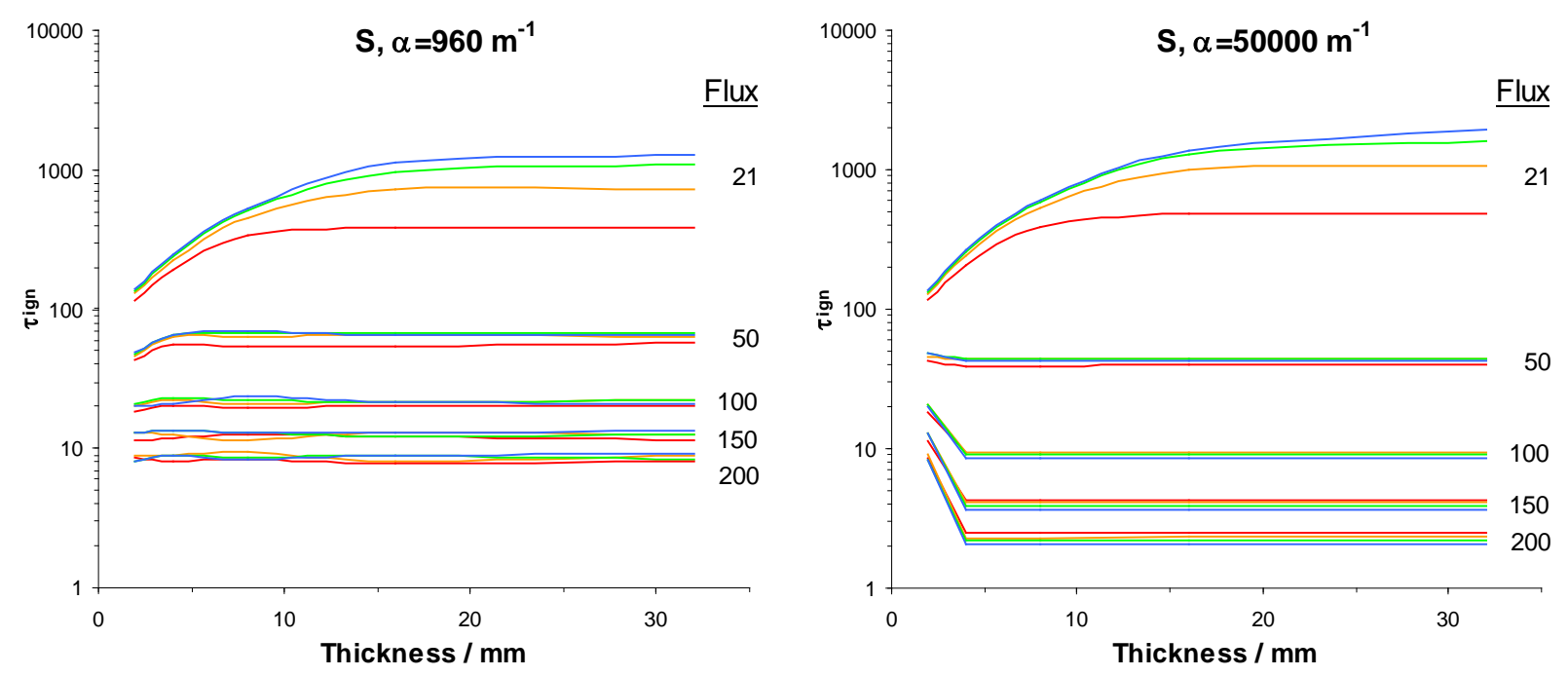

Figure 9 - Ignition time variation for values of the external heat flux of $(21,50,100,150$, and 200$) \mathrm{kW} / \mathrm{m}^{2}$, and

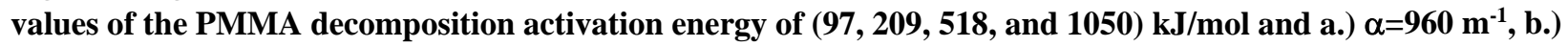
$\alpha=50000 \mathrm{~m}^{-1}$. 


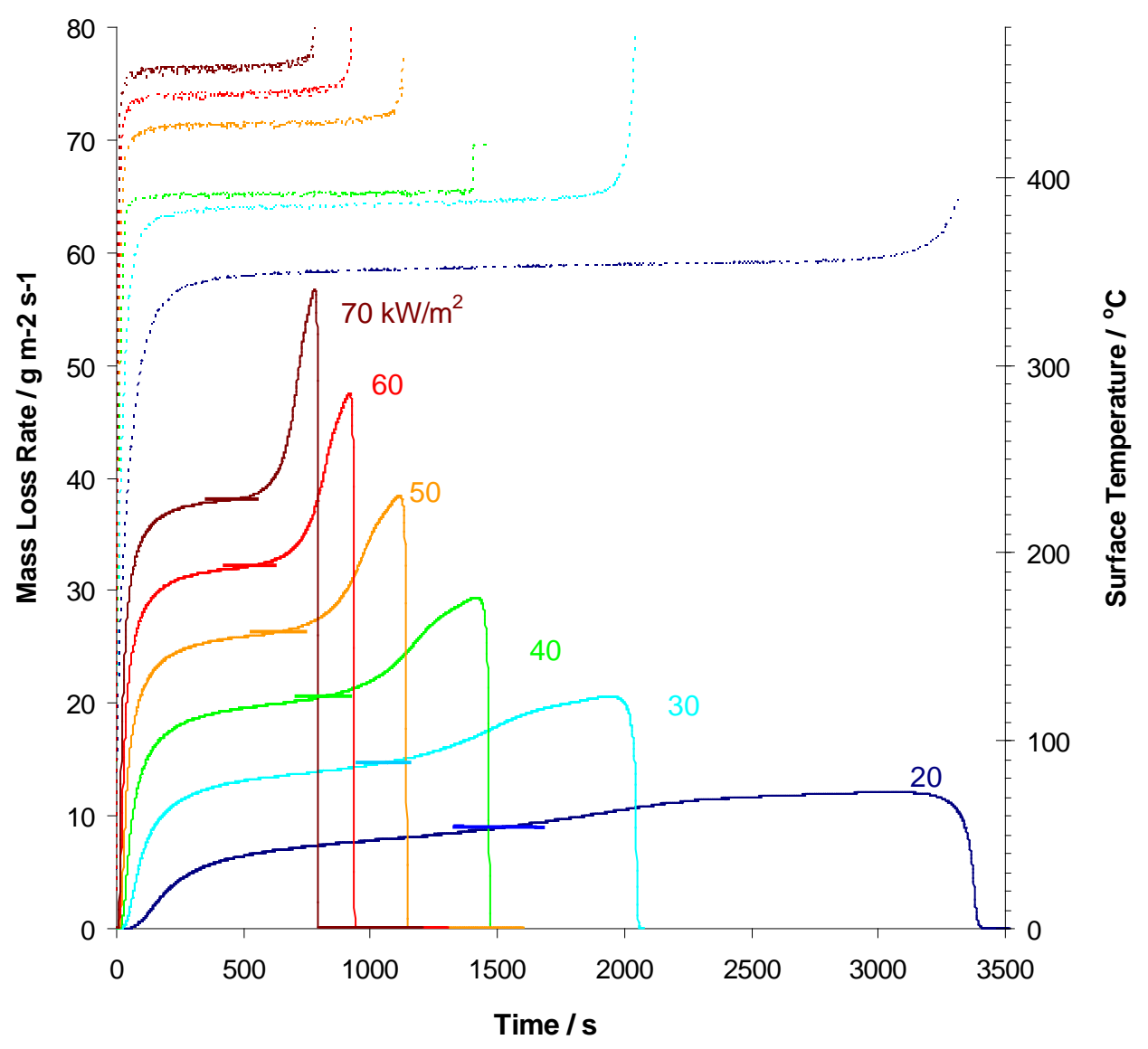

Figure 10 - Calculated mass loss rate (solid lines, left axis) and surface temperature (dotted lines, right axis) as a function of time for $25.4 \mathrm{~mm}$ thick PMMA samples exposed to external radiant fluxes of (20, 30, 40, 50, 60 , and 70$) \mathrm{kW} / \mathrm{m}^{2}$. Horizontal bars are the average burning rate. 


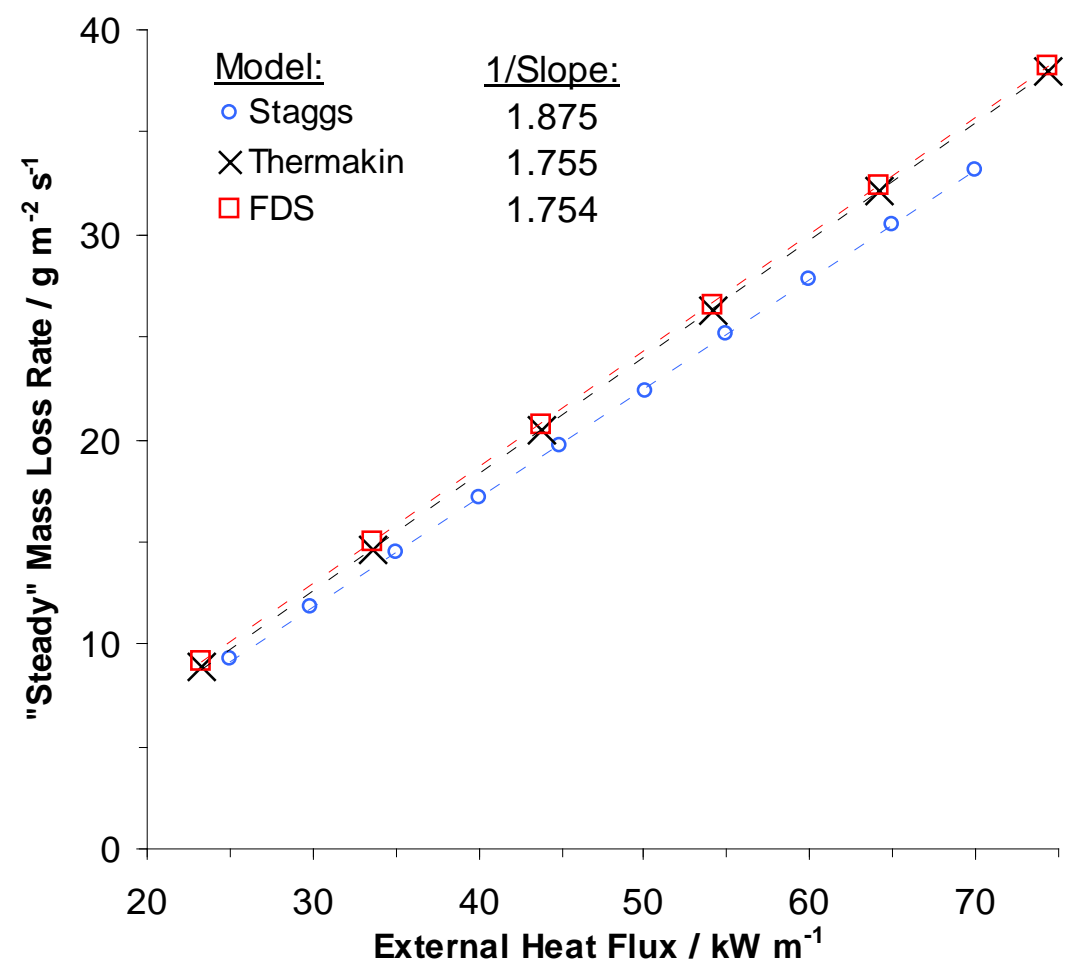

Figure 11 - Calculated mass loss rate as a function of external heat flux for 25.4 mm thick PMMA, from FDS, ThermaKin, and analytic model of Staggs[22] (points: data; dotted lines: linear curve fit). 


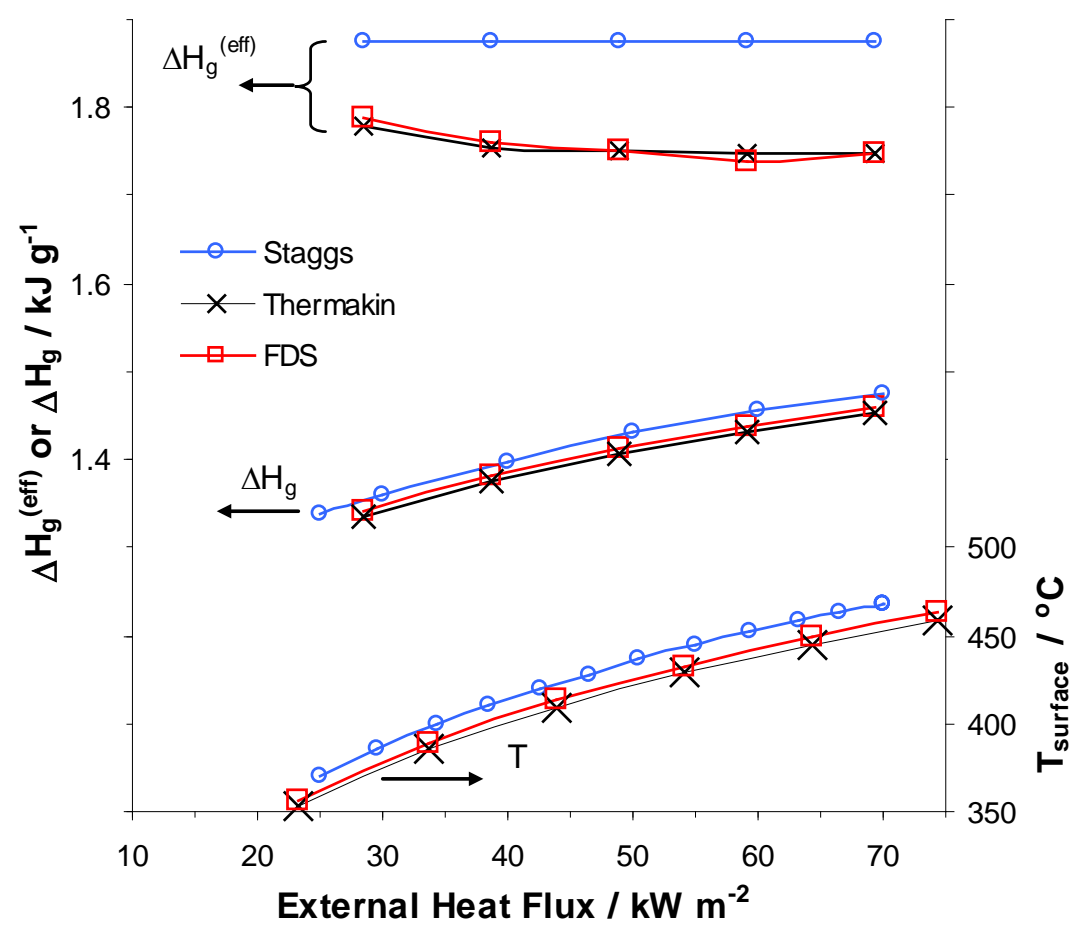

Figure 12 - Calculated heat of gasification $\Delta H_{\mathrm{g}}$ and effective heat of gasification $\Delta \mathrm{H}_{\mathrm{g}}{ }^{\text {(eff) }}$ (left scale), and surface temperature (right scale) as a function of external heat flux for $25.4 \mathrm{~mm}$ thick PMMA, from FDS, ThermaKin, and analytic model of Staggs[22]. 


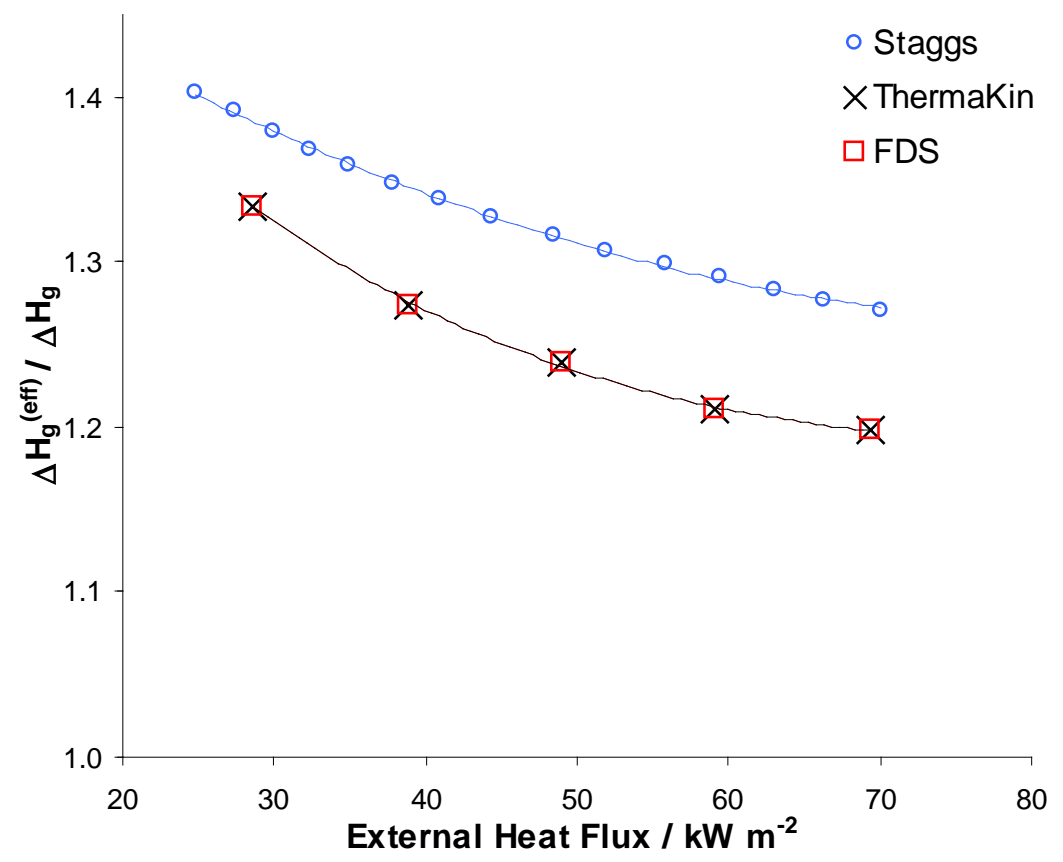

Figure 13 - Ratio of effective heat of gasification $\Delta \mathrm{H}_{\mathrm{g}}{ }^{\text {(eff) }}$ to the heat of gasification $\Delta \mathrm{H}_{\mathrm{g}}$ as a function of external heat flux for $25.4 \mathrm{~mm}$ thick PMMA, from FDS, FAA, and analytic model of Staggs[22]. 


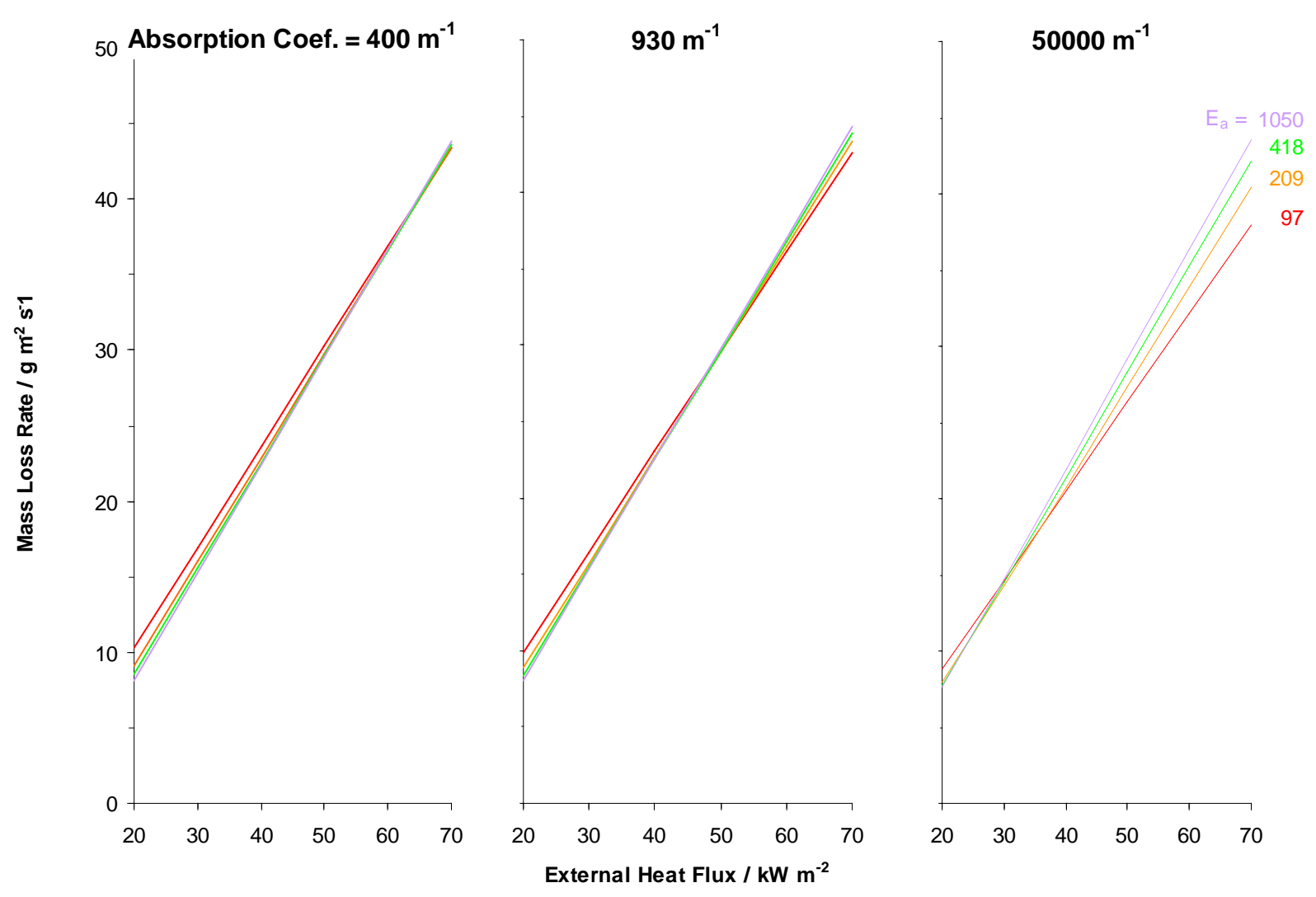

Figure 14 - Calculated mass loss rate as a function of the external heat flux for $25.4 \mathrm{~mm}$ thick PMMA, with values of the absorption coefficient of $(400,930$, and 50000$) \mathrm{m}^{-1}$. In each frame, the different curves correspond to PMMA decomposition activation energies of $(97,209,418$, and 1050) $\mathrm{kJ} / \mathrm{mol}$. 


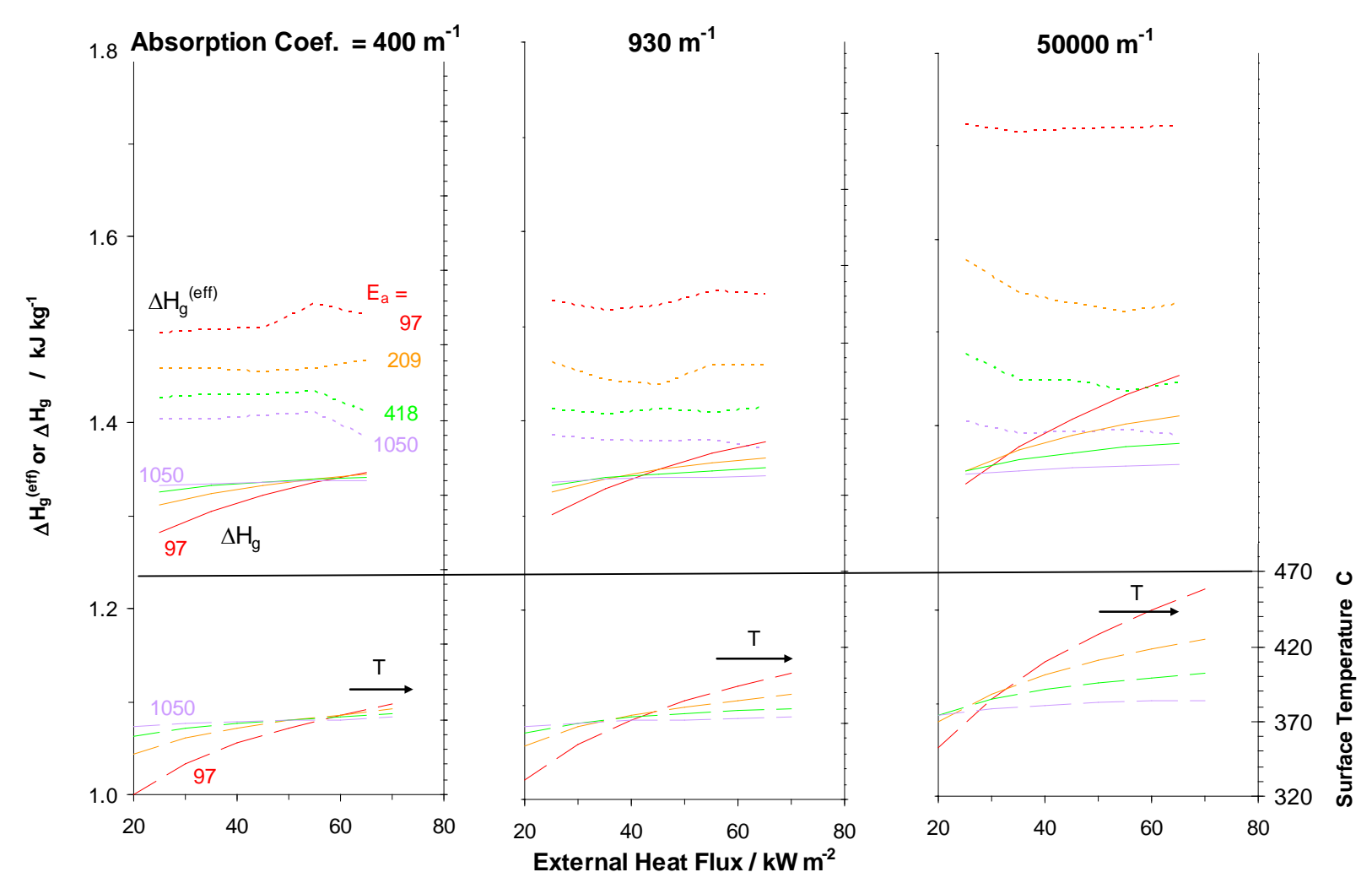

Figure 15 - Calculated effective heat of gasification $\Delta \mathbf{H}_{\mathrm{g}}{ }^{\text {(eff) }}$, heat of gasification $\Delta \mathbf{H}_{\mathrm{g}}$, and polymer surface temperature as a function of the external heat flux for $\mathbf{2 5 . 4} \mathbf{~ m m}$ thick PMMA, with values of the absorption coefficient of $(400,930$, and 50000$) \mathrm{m}^{-1}$. In each frame, the different curves correspond to PMMA decomposition activation energies of $(97,209,418$, and 1050$) \mathrm{kJ} / \mathrm{mol}$. 

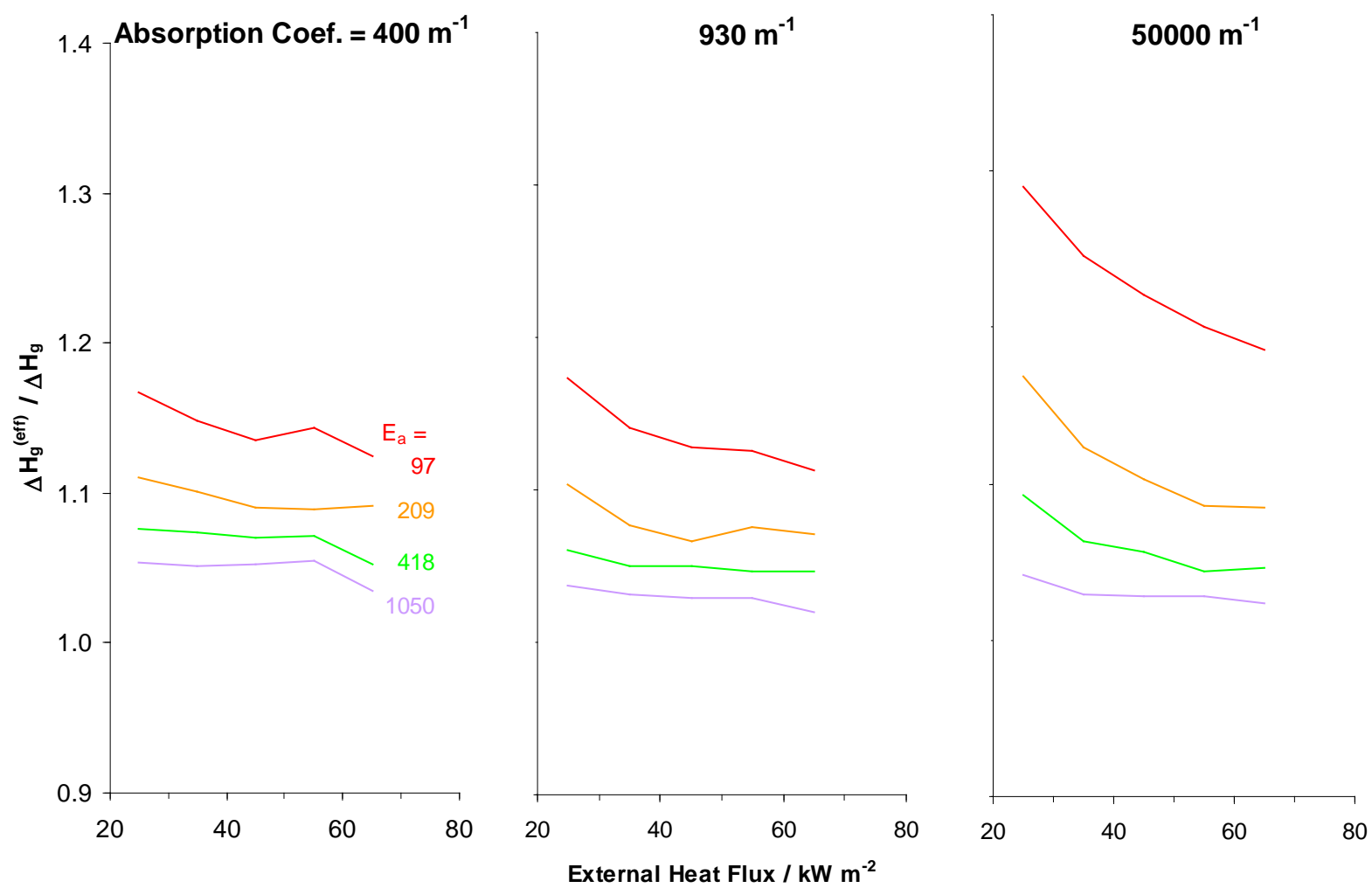

Figure 16 - Calculated ratio of effective heat of gasification $\Delta H_{g}{ }^{\text {(eff) }}$ to the heat of gasification $\Delta H_{g}$ as a function of the external heat flux for $\mathbf{2 5 . 4} \mathbf{~ m m}$ thick PMMA, with values of the absorption coefficient of (400, 930, and 50000) $\mathrm{m}^{-1}$. In each frame, the different curves correspond to PMMA decomposition activation energies of $(97,209,418$, and 1050$) \mathrm{kJ} / \mathrm{mol}$. 

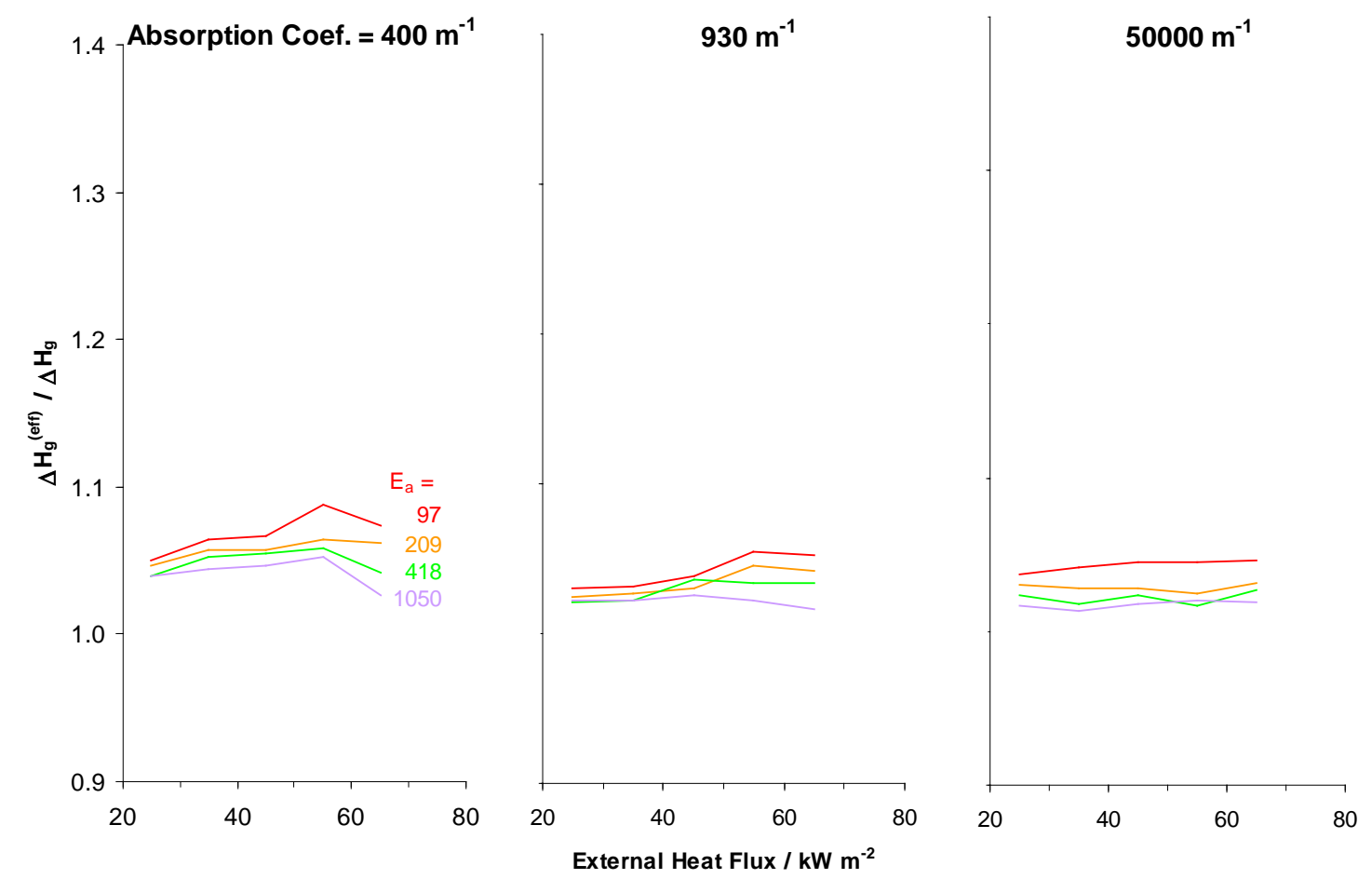

Figure 17 - Calculated ratio of effective heat of gasification $\Delta H_{g}{ }^{\text {(eff) }}$ to the heat of gasification $\Delta H_{g}$ as a function of the net heat flux for $\mathbf{2 5 . 4} \mathbf{~ m m}$ thick PMMA. In each frame, the different curves correspond to PMMA decomposition activation energies of $(97,209,418$, and 1050$) \mathrm{kJ} / \mathrm{mol}$. 